\title{
Juglanin administration protects skin against UVB-induced injury by reducing Nrf2-dependent ROS generation
}

\author{
YING-HUI KONG and SU-PING XU \\ Department of Dermatology, the Affiliated Huaian No. 1 People's Hospital of \\ Nanjing Medical University, Huai'an, Jiangsu 223300, P.R. China
}

Received February 24, 2017; Accepted August 4, 2019

DOI: $10.3892 / \mathrm{ijmm} .2020 .4589$

\begin{abstract}
Extensive solar ultraviolet B (UVB) exposure of the skin results in inflammation and oxidative stress, which may contribute to skin cancer. Natural products have attracted attention for their role in the effective treatment of cutaneous neoplasia. Juglanin is purified from the crude extract of Polygonum aviculare, exhibiting anti-oxidant, anti-inflammatory and anti-cancer activities. Jugalanin was used in the current study to investigate whether it may ameliorate UVB irradiation-induced skin damage by reducing oxidative stress and suppressing the inflammatory response in vivo and in vitro. In the present study, hairless mice were exposed to UVB irradiation in the absence or presence of juglanin administration for 10 weeks. The findings indicated that juglanin inhibited UVB-induced hyperplasia and decreased infiltration in the skin of mice. UVB exposure-induced oxidative stress in mice and cells was inhibited by juglanin via enhancing anti-oxidant activity. Additionally, juglanin markedly reduced pro-inflammatory cytokine release, including cyclic oxidase 2 , interleukin- $1 \beta$ and tumor necrosis factor- $\alpha$, triggered by chronic UVB irradiation. Juglanin-ameliorated skin damage was associated with its suppression of mitogen activated protein kinases (MAPKs), including p38, extracellular signal regulated 1/2, and c-Jun $\mathrm{N}$-terminal kinases, as well as nuclear factor (NF)- $\kappa \mathrm{B}$ signaling pathways, which was dependent on nuclear factor-E2-related factor 2 (Nrf2)-modulated reactive oxygen species generation. Taken together, these data indicate that juglanin protected against UVB-triggered oxidative stress and inflammatory responses by suppressing MAPK and $\mathrm{NF}-\kappa \mathrm{B}$ activation via enhancing Nrf2 activity.
\end{abstract}

Correspondence to: Dr Su-Ping Xu, Department of Dermatology, the Affiliated Huaian No. 1 People's Hospital of Nanjing Medical University, 6 Beijing Road West, Huai'an, Jiangsu 223300, P.R. China E-mail: xusupingnmu@foxmail.com

Key words: ultraviolet B, juglanin, oxidative stress, inflammatory response, nuclear factor-E2-related factor

\section{Introduction}

Ultraviolet B (UVB) radiation (wavelength, 280-315 nm) is reported as the most damaging component of solar radiation reaching the surface of the Earth, predominantly exerting its action on the epidermal layer of the skin $(1,2)$. Extensive exposure of the skin to UVB results in various harmful responses, including edema, sunburn, hyperplasia, inflammation, erythema, as well as immunosuppression, which have been reported in different types of skin disease, and which may eventually develop into skin cancer $(3,4)$. Various molecular mechanisms associated with skin injury induced by UVB have been investigated, including oxidative stress, inflammatory responses and apoptosis (5-7). In the present study, female animal models were used. Previous studies using an SKH-1 mouse model demonstrated that acute UVB exposure induces higher levels of inflammation and lower levels of DNA damage in female mice compared with male mice (8). Furthermore, male SKH-1 mice exhibited a reduced capacity to eliminate reactive oxygen species (ROS) produced following UVB exposure (9), and a reduction of the immunoprotective response following UVA exposure, as well as a reduction of the immunoprotective response following UVA exposure relative to females $(10,11)$.

As previously described, ROS is crucial for skin damage, accounting for $50 \%$ of skin injury due to UVB irradiation (12). Exposure of skin to UVB initiates a photo-oxidative reaction, accelerating cellular ROS levels (13). The redox-sensitive transcription factor, nuclear factor-E2-related factor 2 (Nrf2) is important in modulating ROS production. Nrf2, thus, has been considered as an essential molecular target for various pharmacological prevention strategies in human and animal pathologies due to exposure to environmental toxicants, which involve UV light $(14,15)$. According to a previous study, Nrf2 is proposed as a protective signal in gene expression mediation to inhibit skin damage induced by UV irradiation (16). Therefore, pharmacological modulation of Nrf2 may potentially protect skin from damage by UV exposure. Additionally, skin inflammation is another major mechanism that causes skin injury induced by UV (17). Nuclear factor (NF)-кB), a redox-sensitive transcriptional factor, is critical in the pathogenesis of UVB-triggered inflammation, which is linked to skin carcinogenesis (18). NF- $\mathrm{kB}$ activation modulates inflammatory responses by enhancing pro-inflammatory cytokine 
secretion, including tumor necrosis factor (TNF)- $\alpha$, interleukin (IL)-1 $\beta$ and cyclic oxidase 2 (COX2) $(19,20)$. Hence, $\mathrm{NF}-\kappa \mathrm{B}$ inactivation blocks inflammatory responses induced by UVB irradiation.

Juglanin (Fig. 1A), as a natural compound extracted from the crude Polygonum aviculare, displayed inhibitory activity against the inflammatory response, dependent on NF- $\kappa B$ de-phosphorylation, as well as anticancer activity through regulating ROS production with little cytotoxicity on normal cells (21-23). Considering its effect on inflammation and ROS, in the current study, the effects of juglanin on skin damage induced by UVB were investigated. The underlying molecular mechanisms were also further explored in vitro and in vivo.

\section{Materials and methods}

Animals and treatment. Sixty female, SKH-1 hairless mice (age, 6-8 weeks; weight, 18-20 g) were purchased from the Shanghai Laboratory Animal Research Center (Shanghai, China). The mice were acclimatized for 1 week prior to the experiments in specific pathogen-free (SPF) conditions in static micro-isolator cages with access to tap water ad libitum and maintained under standard conditions (12-h light/dark cycle; 8:00 a.m. to 8:00 p.m.) at a temperature of $23 \pm 2^{\circ} \mathrm{C}$ and relative humidity of $50 \pm 5 \%$. All animal experiments were conducted according to the Guide for the Care and Use of Laboratory Animals, issued by the National Institutes of Health in 1996 and approved by the Institutional Animal Ethics Committee for the Guide for the Care and Use of Laboratory Animals of Huai'an First People's Hospital, Nanjing Medical University (Huai'an, China). SKH-1 hairless mice were then randomly divided into 4 groups with 15 mice per group. Mice were exposed to UVB lamps (GL20SE; Sankyo Denki Co., Ltd., Kanagawa, Japan) equipped with a controller to modulate UV dosage, with a distance of $20 \mathrm{~cm}$ between the target skin and the light source. The treatment groups ( $\mathrm{n}=15$ per group) were as follows: Group 1, untreated animals (Con); group 2, animals irradiated with UVB only (UVB); group 3, UVB irradiation with application of $15 \mathrm{mg} / \mathrm{kg}$ juglanin (cat. no. 5041-67-8; purity $\geq 98 \%$; Shanghai YuanMu Biological Technology Co., Ltd., Shanghai, China) by gavage (UVB+15); group 4 , UVB irradiation with application of juglanin $(30 \mathrm{mg} / \mathrm{kg})$ by gavage $(\mathrm{UVB}+30)$, which was subsequent to $30 \mathrm{~min} \mathrm{UVB}$ $\left(50 \mathrm{~mJ} / \mathrm{cm}^{2}\right)$. Murine skin exposure consisted of $50 \mathrm{~mJ} / \mathrm{cm}^{2}$ UVB following juglanin treatment for $1 \mathrm{~h}, 3$ times per week for 10 consecutive weeks. During the period of exposure, mice were individually housed in stainless steel chambers. A non-irradiated group of animals was included as a UVB negative control. After 10 weeks of exposure with or without juglanin treatment, the animals were euthanized $24 \mathrm{~h}$ after the final UVB irradiation, and the dorsal skin tissues from the mice were excised, maintained in liquid nitrogen and stored at $-80^{\circ} \mathrm{C}$ for subsequent research. A total of 6 skin tissue samples $\left(1 \times 1 \mathrm{~cm}^{2}\right)$ were selected randomly and fixed in $4 \%$ formalin for $48 \mathrm{~h}$ at room temperature and subsequently embedded in paraffin for immunohistochemical analysis.

Cell culture and treatment. Human epidermal cells, HaCaT, were purchased from the American Type Culture Collection (Manassas, VA, USA). Cells were cultured in Dulbecco's modified Eagle's medium supplemented with $10 \%$ fetal bovine serum (Invitrogen; Thermo Fisher Scientific, Inc., Waltham, MA,USA), penicillin (100 U/ml) and streptomycin $(100 \mu \mathrm{g} / \mathrm{ml})$ at $37^{\circ} \mathrm{C}$ in an atmosphere of $5 \% \mathrm{CO}_{2}$. The $\mathrm{HaCaT}$ cells were cultured until $80 \%$ confluence and then pretreated with various concentrations of juglanin (80 and $160 \mu \mathrm{M})$. Following a 12-h incubation at $37^{\circ} \mathrm{C}$, the culture medium was replaced with $1.5 \mathrm{ml}$ phosphate-buffered saline (PBS). HaCaT cells were then exposed to $15 \mathrm{~mJ} / \mathrm{cm}^{2} \mathrm{UVB}$ (light source, $312 \mathrm{~nm}$ ). After UVB exposure, the cells were treated with various concentrations of juglanin (80 and $160 \mu \mathrm{M}$ ) in serum-free DMEM medium (Gibco; Thermo Fisher Scientific, Inc.) for another $12 \mathrm{~h}(21,23)$. Mitogen activated protein kinases (MAPK) inhibitors of SB203580 [high-performance liquid chromatography (HPLC) $\geq 98 \%$ ], PD98059, SP600125 (HPLC, $\geq 98 \%$ ), and NF- $\kappa B$ (p65) inhibitor, JSH-23 (HPLC, $\geq 98 \%$ ), were purchased from Sigma-Aldrich (Merck KGaA, Darmstad, Germany). The inhibitors were dissolved in dimethyl sulfoxide (DMSO; Beyotime Institute of Biotechnology, Shanghai, China) and added to the culture media. The cells were pre-treated with each inhibitor at the indicated concentrations [SB203580 $(50 \mathrm{nM}), \mathrm{PD} 98059(10 \mathrm{nM})$ and SP600125 $(50 \mu \mathrm{M})]$ for $1 \mathrm{~h}$ and/or with juglanin for $12 \mathrm{~h}$, and exposed to $15 \mathrm{~mJ} / \mathrm{cm}^{2} \mathrm{UVB}$ irradiation for $24 \mathrm{~h}$, followed by incubation for another $12 \mathrm{~h}$ in the absence or presence of juglanin $(160 \mu \mathrm{M})$ at $37^{\circ} \mathrm{C}$. After $48 \mathrm{~h}$ treatment, the cells were harvested for further study.

Intracellular ROS analysis. Following incubation with various concentrations of juglanin $(0,80$ and $160 \mu \mathrm{M})$, $5 \times 10^{5}$ cells $/ 200 \mu 1 \mathrm{HaCaT}$ cells were re-incubated with dihydroethidium (DHE) for $10 \mathrm{~min}$ at room temperature using a Reactive Oxygen Species Assay kit (cat. no. C1300; BestBio, Shanghai, China) according to the manufacturer's protocol in Hanks' balanced salt solution for $30 \mathrm{~min}$ at $37^{\circ} \mathrm{C}$. Following incubation, the fluorescence of DHE was measured spectro-fluorimeterically at $535 \mathrm{~nm}$ excitation and $610 \mathrm{~nm}$ emission wavelengths.

Cell viability assays. A 3-(4,5-dimethylthiazol-2-yl)-2,5-diphenyltetrazolium bromide (MTT; cat. no. C0009; Beyotime Institute of Biotechnology) colorimetric assay kit was used to measure cell viability, according to the manufacturer's protocol. A total of $10^{3} \mathrm{HaCaT}$ cells were maintained until $80 \%$ confluence and then pretreated with different concentrations $(0,5,10,20,40,80$ and $160 \mu \mathrm{M})$ of juglanin for various durations $(0,6,12,24,36$ and $48 \mathrm{~h})$. Cell medium was replaced with $150 \mu 1 \mathrm{MTT}$ and incubated at $37^{\circ} \mathrm{C}$ for an additional $4 \mathrm{~h}$. Once the $\mathrm{HaCaT}$ cells were washed using PBS twice, the insoluble formazan crystals were dissolved in $200 \mu \mathrm{l}$ DMSO. The absorbance was read by spectrophotometry at a wavelength of $540 \mathrm{~nm}$ using a Multiskan EX microplate reader (Thermo Fisher Scientific, Inc.). The data were represented as percentage cell viability compared with the untreated control group.

Biochemical indicator analysis. The activities of enzymatic antioxidants in skin tissue samples, including superoxide dismutase (SOD), catalase (CAT) and glutathione peroxides (GPx) were analyzed using SOD (cat. no. A001-1-1), CAT (cat. no. A007-1-1) and GPx (cat. no. A005) assay kits (all from 
A<smiles>O=c1c(OC2OC(CO)[C@@H](O)[C@H]2O)c(-c2ccc(O)cc2)oc2cc(O)cc(O)c12</smiles>

B
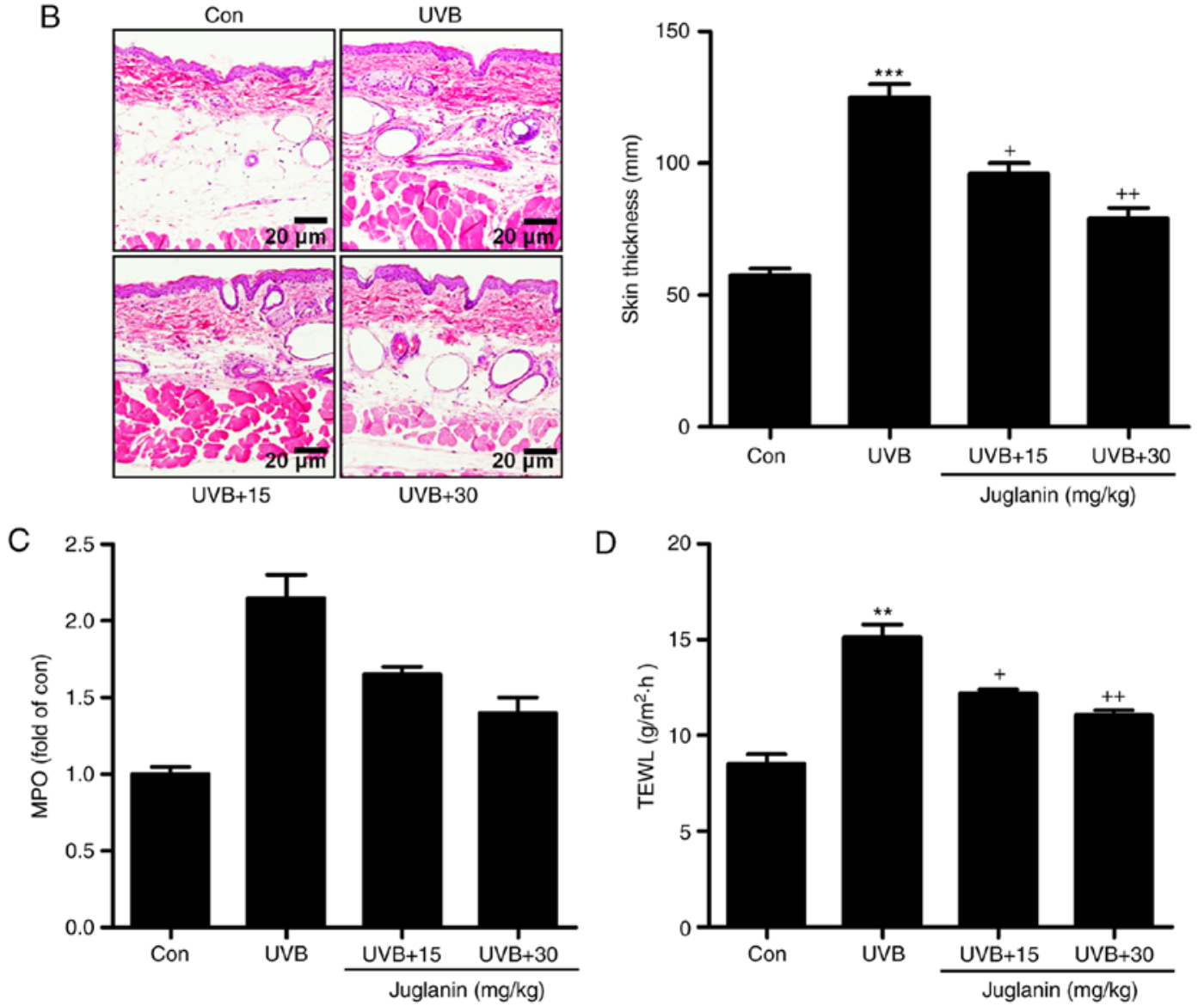

Figure 1. Juglanin suppresses UVB-induced skin injury in a mouse model. (A) Chemical structure of juglanin. (B) Representative images of mouse skin samples from each group (Con, UVB, UVB+15, and UVB+30) via hematoxylin and eosin staining analysis. The epidermal thickness was also quantified. (C) MPO levels were calculated in each group of mice. (D) TEWL levels were measured in the hairless mice treated under various conditions. Data are presented as the mean \pm standard error of the mean $(\mathrm{n}=8) .{ }^{* *} \mathrm{P}<0.01$ and ${ }^{* * *} \mathrm{P}<0.001$ vs. the Con group. ${ }^{+} \mathrm{P}<0.05$ and ${ }^{++} \mathrm{P}<0.01$ vs. the $\mathrm{UVB}$ group. $\mathrm{UVB}$, ultraviolet $\mathrm{B}$; MPO, myeloperoxidase; TEWL, transepidermal water loss; Con, control; UVB+15, UVB treatment plus juglanin administration (15 mg/kg); UVB+30, UVB treatment plus juglanin administration $(30 \mathrm{mg} / \mathrm{kg})$.

Nanjing Jiancheng Bioengineering Institute, Nanjing, China), respectively. The levels of reduced glutathione (GSH) and malondialdehyde (MDA) in skin tissue samples were measured using GSH (cat. no. A006-2) and MDA (cat. no. A003-1) assay kits (Nanjing Jiancheng Bioengineering Institute) according to the manufacturer's protocol. The thiobarbituric acid reactive substance (TBARS) levels in the skin tissues were calculated using a mouse TBARS ELISA kit (cat. no. xy-E10068; Runyubio-Technology Co., Ltd., Shanghai, China) according to the manufacturer's protocol.

ELISA for transforming growth factor- $\beta 1$ (TGF- $\beta 1$ ) assessment. The skin samples were frozen in liquid nitrogen and crushed into a powder using a multibead shocker. The powder was dissolved in cell lysis buffer for Western and IP (Beyotime Institute of Biotechnology) with protease inhibitor cocktail (Roche Diagnostics, Indianapolis, IN, USA). The skin extract was prepared by centrifugation at $12,000 \mathrm{x}$ g for $10 \mathrm{~min}$ at $4^{\circ} \mathrm{C}$, and the supernatant was stored for further experiments. The sample protein concentrations were calculated using a BCA protein assay kit (cat. no. 23250; Thermo Fisher Scientific Inc.) according to the manufacturer's protocol. TGF- $\beta 1$ protein expression levels were assessed using a Mouse ELISA kit (R\&D Systems, Inc., Minneapolis, MN, USA) according to the manufacturer's protocol.

Transepidermal water loss (TEWL) analysis. TEWL $\left(\mathrm{g} / \mathrm{m}^{2} / \mathrm{h}\right)$ is a marker of epidermal skin barrier function, and was 
measured using a Tewameter ${ }^{\mathrm{TM}} 300$ (Courage + Khazaka Electronic GmbH, Köln, Germany). Briefly, under isoflurane anesthesia, a medical adhesive tape (Honsmed, Shanghai, China) was used to apply a gentle pressure on the mouse skin; then it was removed. Mice were tape-stripped 5 times. TEWL was then recorded using a Tewameter ${ }^{\mathrm{TM}} 300$.

Calculation of wrinkle formation in the dorsal skin. The dorsal skin samples of mice were collected following the final UVB irradiation and replicated using a silicone product under isoflurane anesthesia. The representative images of the mouse skin replica were analyzed using a 3D Magic Mirror Skin Analyzer Machine SW-26A equipped with Skin-Visiometer VL 650 software (Sunwein-tech, Guangdong, China). The parameters to evaluate skin wrinkles were wrinkle volume ratio, wrinkle area ratio, total groove volume ratio and the number of wrinkles.

Assessment of ROS generation. ROS generation in cells was measured with DHE using a Dihydroethidium kit (cat. no. S0063; Beyotime Institute of Biotechnology), purchased from Beyotime Institute of Biotechnology according to the manufacturer's protocol. Following the various treatments, cells were incubated with DHE $(10 \mu \mathrm{M})$ for $30 \mathrm{~min}$ under $37^{\circ} \mathrm{C}$, and the cells were washed with serum-free DMEM medium three times. The fluorescence intensity was observed under a confocal microscope (Olympus Corporation, Tokyo, Japan) at a magnification of x200.

Immunohistochemical (IHC) analysis. The fixed skin tissue samples obtained from mice were embedded in paraffin blocks following euthanasia. Skin samples were dehydrated in ascending concentrations of ethanol (80,95 and 100\%), cleared in xylene, embedded in Paraplast (Sigma Aldrich; Merck $\mathrm{KGaA}$ ) and $3-\mu \mathrm{m}$ thick sections were cut. Skin sections were deparaffinized and stained for $15 \mathrm{~min}$ with hematoxylin and eosin (H\&E) at room temperature. The thickness of the skin epidermis was assessed using Magnuspro software (version 3.0; Plan Achromate, Olympus, Germany). Epidermal thickness of the H\&E-stained sections was further assessed with ImageJ Software (version 1.47; National Institutes of Health, Bethesda, MD, USA). For immunohistochemical images, the skin tissue sections were exposed to $\mathrm{HCl}(3.5 \mathrm{M})$ for $20 \mathrm{~min}$ at room temperature and washed using PBS three times. Subsequently, the skin tissue sections were treated with peroxidase $(0.3 \%)$ to diminish endogenous peroxidase activity. Tissue sections were incubated with normal goat serum (5\%) for $30 \mathrm{~min}$ followed by incubation with primary antibodies [inducible nitric oxide synthase (iNOS; cat. no. 13120) and TGF- $\beta 1$ (cat. no. 3711); Cell Signaling Technology, Inc., Danvers, MA, USA)] at 1:100 dilution for $2 \mathrm{~h}$ at room temperature. The section was then incubated with goat anti-rabbit immunoglobulin G (IgG) horseradish peroxidase (HRP)-conjugated secondary antibody (1:250; cat. no. 150077; Abcam, Cambridge, MA, USA) at room temperature for $30 \mathrm{~min}$. Diaminobenzidine (ChemService, Inc., West Chester, PA, USA) served as the chromogen according to the manufacturer's protocol.

Immunofluorescent analysis of skin tissue. The skin tissue sections were dried for $10 \mathrm{~min}$ at room temperature, fixed with chilled acetone for $10 \mathrm{~min}$ at $-20^{\circ} \mathrm{C}$, and washed with PBS three times (5 min per wash). The pre-incubation was conducted with 5\% normal rabbit serum (SouthernBiotech, Birmingham, AL, USA) at room temperature for $1 \mathrm{~h}$, and sections were incubated with the respective specific antibodies: Polyclonal rabbit anti-phosphorylated (p)-NF- $\mathrm{B}$ (cat. no. 86299; dilution, 1:50; Abcam), polyclonal rabbit anti-iNOS (cat. no. 13120; dilution, 1:100; CST Biological Reagents Co., Ltd., Shanghai, China) at $4^{\circ} \mathrm{C}$ overnight. Subsequently, the slides were washed with PBS three times and treated with HRP-conjugated anti-rabbit monoclonal IgG secondary antibody (cat. no. A0208; dilution: 1:200; Beyotime Institute of Biotechnology) for $15 \mathrm{~min}$ at room temperature. Sections were counterstained for cell nucleus detection using 4',6-diamidino-2-phenylindole (Thermo Fisher Scientific, Inc.) solution for $5 \mathrm{~min}$ at room temperature, washed with PBS three times (5 min per wash), and mounted in 17984-25-Fluoromount- $\mathrm{G}^{\mathrm{TM}}$ Slide Mounting Medium (Southern Biotech, Birmingham, AL, USA). All fluorescent images were obtained using a fluorescence microscope (BX53, Olympus, Japan) at a magnification of x200.

Determination of myeloperoxidase (MPO) activity. Tissue MPO was evaluated according to the protocol provided by the MPO kit's manufacturer (USCNK, Wuhan, China). This assay provides a fluorescence-based method for detecting the MPO activity in tissue lysates.

Western blot analysis. Following various cell treatments as described previously in the cell culture and treatment sections, all $\mathrm{HaCaT}$ cells were collected for western blot analysis. Briefly, $\mathrm{HaCaT}$ cells were pelleted and lysed with cell lysis reagent $(0.216 \%$ Beta glycerophosphate, $0.19 \%$ Sodium orthovanadate, $0.001 \%$ Leupeptin, $0.38 \%$ EGTA, $10 \%$ Triton-X-100, 3.15\% Tris HCl, $8.8 \%$ Sodium chloride, $0.29 \%$ Sodium EDTA, $1.12 \%$ Sodium pyrophosphate decahydrate; Beyotime Institute of Biotechnology) in the presence of protease inhibitor cocktail (Beyotime Institute of Biotechnology). Mice were euthanized and dorsal-skin tissue samples were isolated. The skin tissue samples were homogenized into $10 \%(\mathrm{w} / \mathrm{v})$ hypotonic buffer [25 mM Tris- $\mathrm{HCl}$ (pH 8.0), $1 \mathrm{mM}$ EDTA, $5 \mu \mathrm{g} / \mathrm{ml}$ leupeptin, $1 \mathrm{mM}$ Pefabloc SC, $50 \mu \mathrm{g} / \mathrm{ml}$ aprotinin, $5 \mu \mathrm{g} / \mathrm{ml}$ soybean trypsin inhibitor and $4 \mathrm{mM}$ benzamidine] to yield a homogenate. The final supernatants from the cells and skin tissue samples were obtained by centrifugation at $12,000 \mathrm{xg}$ for $20 \mathrm{~min}$ at $4^{\circ} \mathrm{C}$. Protein content was calculated using a BCA Protein Assay kit (cat. no. 23250; Thermo Fisher Scientific, Inc.). The extracted proteins were denatured at $100^{\circ} \mathrm{C}$ for $5 \mathrm{~min}$. Proteins $(40 \mu \mathrm{g} /$ well) were loaded in 10\% Tris-SDS gel and transferred to polyvinylidene difluoride membranes, (EMD Millipore, Billerica, MA, USA) using the wet transfer system. After blocking for $2 \mathrm{~h}$ at $37^{\circ} \mathrm{C}$ with $5 \%$ skimmed milk in Tris-buffered saline with $0.1 \%$ Tween-20, the membranes were incubated overnight at $4^{\circ} \mathrm{C}$ with anti-protein primary antibodies against p-NF- $\mathrm{kB}$ (cat. no. ab86299; dilution, 1:1,000), NF-kB (cat. no. ab16502; dilution, 1:1,000) (both from Abcam), p-ERK1/2 (cat. no. 8544; dilution, 1:1,000), ERK1/2 (cat. no. 4695; dilution, 1:1,000) (both from CST Biological Reagents Co., Ltd.), p-JNK (cat. no. ab47337; dilution, 1:1,000), Nrf2 (cat. no. ab62352; dilution, 1:1,000), JNK (cat. no. 112501; dilution 1:1,000) (all from Abcam), p-p38 (cat. no. 4511; dilution, 1:1,000), p38 (cat. no. 8690; dilution, 1:1,000), COX2 
Table I. Primer sequences for the reverse transcription-polymerase chain reaction.

Primer $\left(5^{\prime} \rightarrow 3^{\prime}\right)$

Items

Forward

Reverse

Cyclic oxidase 2

Interleukin- $1 \beta$

Tumor necrosis factor- $\alpha$

Superoxide dismutase 1

Superoxide dismutase 2

Catalase

Nuclear factor-E2-related factor 2 GAPDH

TTATAGATTGATACTCACCA
TGGCCTGACCACAGGAGTTA
GCTCTTCTCTGTCGTGTCTGCC
AGCATCCAAGTGGCAGTAA
GTCTGTAGACACCGCACA
AGAGAGCTCGATGTTACG
CCAGCCGTTCTACTTCCAC
AGAATGGCAGCTTGTGCGTG

TTATAGATTGATACTCACCA

TGGCCTGACCACAGGAGTTA

GCTCTTCTCTGTCGTGTCTGCC

AGCATCCAAGTGGCAGTAA

GTCTGTAGACACCGCACA

CCAGCCGTTCTACTTCCAC

AGAATGGCAGCTTGTGCGTG
AGTGACAGTAGATCTGAGG

CTTCCGTGACTTAGTATACTAT

AATGTATTGTTGGAATTATAC

AGACCAACGACCAGCTCAG

CGAGGCCATAACTGTGACT

CCTTCTCGTCTGACACTGAG

GGAAGCACTCCAGTGGACTA

CTTGGAGGTGCCAACACCTC (cat. no. 12282; dilution, 1:1,000), IL-1 $\beta$ (cat. no. 12703; dilution, 1:1,000), TNF- $\alpha$ (cat. no. 11948; dilution, 1:1,000), iNOS (cat. no. 13120; dilution, 1:1,000), TGF- $\beta 1$ (cat. no. 3711; dilution, 1:1,000) (all from CST Biological Reagents Co., Ltd.), and GAPDH (cat. no. sc293335; dilution, 1:500; Santa Cruz Biotechnology, Inc., Dallas, TX, USA) in blocking buffer. The membrane was then incubated for $3 \mathrm{~h}$ at room temperature with secondary anti-primary immunoglobulin G-conjugated with HRP (dilution, 1:5,000; cat. no. GTX213110-01; GeneTex, Inc., Irvine, CA, USA), followed by application of immobilon Western Chemiluminescent HRP substrate (EMD Millipore). Western blot bands were observed using an ECL Western Blotting Analysis System (GE Healthcare, Chicago, IL, USA) and exposed to X-ray films (Kodak, Rochester, NY, USA) for protein expression analysis (using ImageJ software version $1.47 \mathrm{~d}$; National Institutes of Health, Bethesda, MD, USA).

Small interfering RNA (siRNA) treatment. The HaCaT cells $\left(4.0 \times 10^{5}\right)$ were cultured at $37^{\circ} \mathrm{C}$ in 6 -well plates for $24 \mathrm{~h}$. Then, Nrf2 siRNA (Nrf2 siRNA, 5'-AUGGGCUACUCG GCUAGCAAU-3; negative control, 5'-UGUAAUGGUGCC CAGACCG-3') were added to the cells using the transfection reagent Lipofectamine ${ }^{\circledR} 2000$ (Invitrogen; Thermo Fisher Scientific, Inc.) according to the manufacturer's protocol. A final concentration of $50 \mathrm{nM}$ was prepared in the 6-well plates.

Reverse transcription-quantitative polymerase chain reaction $(R T-q P C R)$ analysis. Total RNA was isolated from the skin tissue samples and $\mathrm{HaCaT}$ cells using the TRIzol reagent (Nanjing KeyGen Biotech Co., Ltd., Nanjing, China). RT-PCR was conducted using the PrimeScript RT Reagent kit (Takara Biotechnology Co., Ltd., Dalian, China) according to the manufacturer's protocol and cDNA then served as the template for subsequent reactions. RT-qPCR was conducted with SYBR Premix Ex Taq II obtained from Takara Biotechnology Co., Ltd. The ABI-Prism 7500 Sequence Detection System (Applied Biosystems; Thermo Fisher Scientific, Inc.) according to the manufacturer's protocol. The primer sequences used in the current study were commercially synthesized and presented in Table I. The mRNA level of GAPDH served as the loading control. The $2^{-\Delta \Delta \mathrm{Cq}}$ method was applied to evaluate the fold changes of mRNA levels in each group (24).
Statistical analysis. Data were expressed as the mean \pm standard error of the mean. Statistical analyses were performed using GraphPad Prism (version 6.0; GraphPad Software, Inc., La Jolla, CA, USA) by one-way analysis of variance with Dunnet's least significant difference post-hoc test. $\mathrm{P}<0.05$ was considered to indicate a statistically significant difference.

\section{Results}

Juglanin suppresses UVB-induced skin injury in a mouse model. Irradiation of UVB has been reported to cause hyperplasia, cutaneous edema, leukocyte infiltration, vascular hyperpermeability and erythema $(3,5)$. Thus, it is necessary to establish an effective treatment. In the present study, the role of juglanin (Fig. 1A) in UVB-induced skin damage was investigated in hairless mice. As demonstrated in Fig. 1B, UVB exposure led to skin damage with higher skin thickness compared with the control group, which was significantly reduced by juglanin administration $(\mathrm{P}<0.05$ and $\mathrm{P}<0.01$ compared with the UVB group), as demonstrated by $\mathrm{H} \&$ E staining, indicating that juglanin ameliorated UVB-induced hyperplasia and cell infiltration in the dermis of skin. MPO is considered to be a marker of cutaneous infiltration induced by UVB exposure (25). The current study identified that MPO was upregulated by 2 .0-fold in UVB-induced skin when compared with the control group, indicating MPO activity resulting from UVB exposure. Notably, juglanin treatment reduced MPO in hairless mice with UVB induction (Fig. 1C). Finally, in order to investigate the epidermal permeability barrier function, the TEWL of the stratum corneum was measured following UVB induction with or without juglanin administration. As presented in Fig. 1D, TEWL was highly increased for UVB irradiation, which was suppressed by exposure to juglanin. Thus, juglanin may contribute to improvement of skin injury induced by UVB irradiation.

Effects of juglanin treatment on UVB-induced wrinkle progression in hairless mice. The process of wrinkle formation may indicate the extent of skin damage (26). The levels of wrinkle formation were evaluated in the present study. In Fig. 2A, deep coarse wrinkles were observed to be formed in mice following UVB exposure, which was attenuated following juglanin administration. The extent of wrinkle formation was analyzed using a 3D image analysis system. The ratios of 

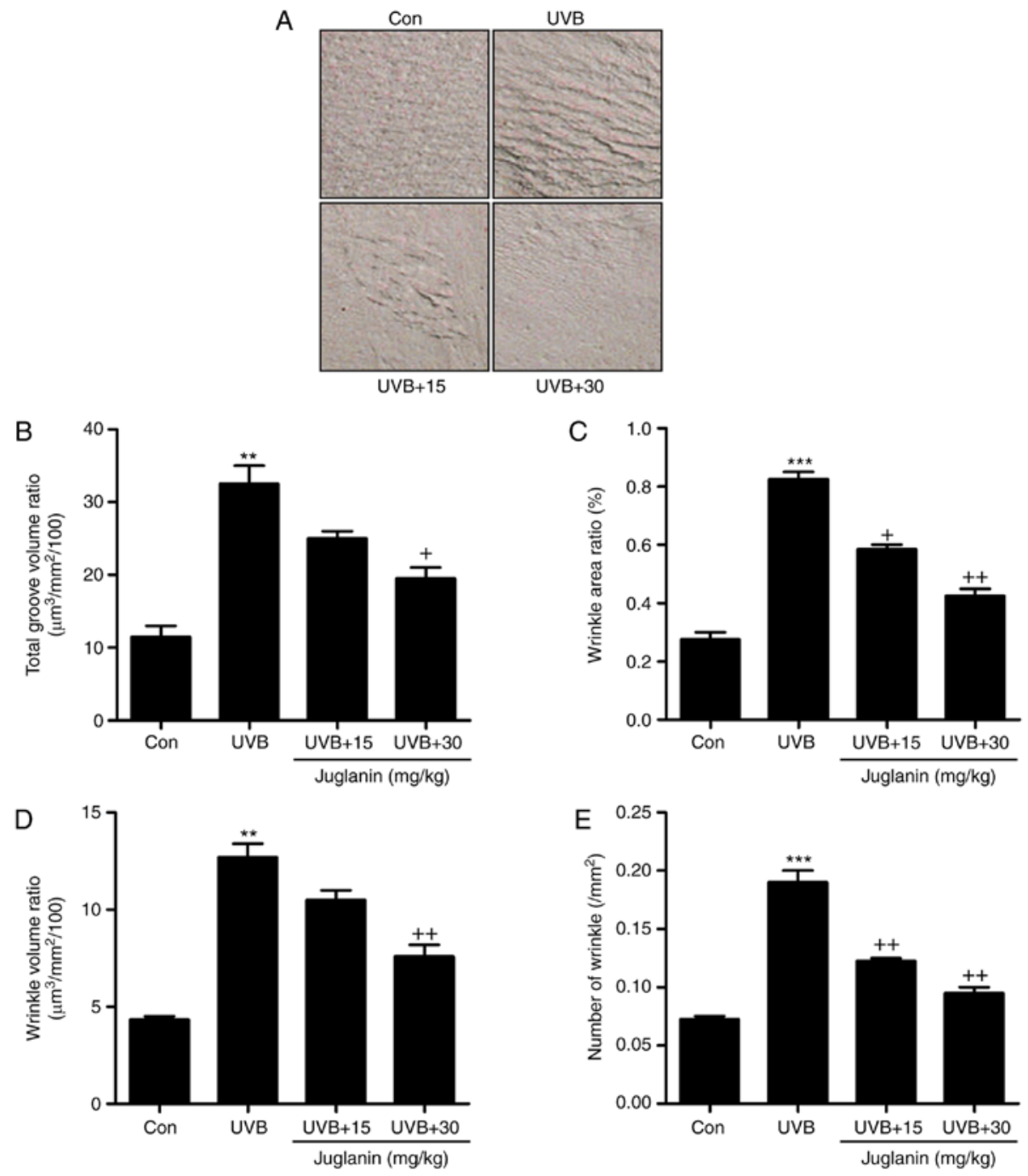

Figure 2. Effects of juglanin treatment on UVB-induced wrinkle progression in hairless mice. (A) Representative images of the skin from mice in each group treated under different conditions. (B) Total groove volume ratio, (C) wrinkle area ratio, (D) wrinkle volume ratio, and (E) the number of wrinkles were evaluated. Data are presented as the mean \pm standard error of the mean $(n=8) .{ }^{* *} \mathrm{P}<0.01$ and ${ }^{* * * *} \mathrm{P}<0.001$ vs. the Con group. ${ }^{+} \mathrm{P}<0.05$ and ${ }^{++} \mathrm{P}<0.01 \mathrm{vs}$. the $\mathrm{UVB}$ group. UVB, ultraviolet B; Con, control.
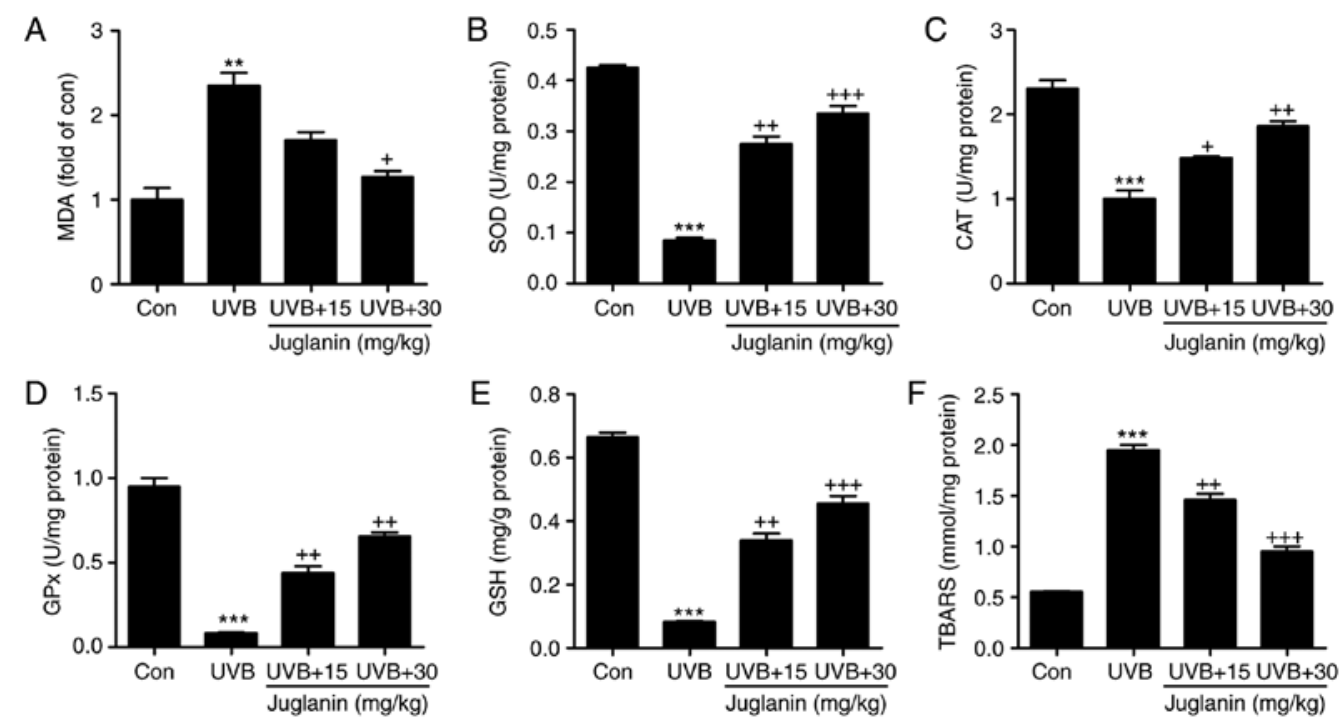

Figure 3. Role of juglanin in UVB-induced MDA, anti-oxidants and TBARS levels in hairless mice. (A) MDA levels, and (B) SOD, (C) CAT, and (D) GPx activity, and (E) GSH and (F) TBARS levels in the skin tissue of hairless mice treated under different conditions. Data are presented as the mean \pm standard error of the mean $(\mathrm{n}=8)$. ${ }^{* *} \mathrm{P}<0.01$ and ${ }^{* * * *} \mathrm{P}<0.001$ vs. the Con group. ${ }^{+} \mathrm{P}<0.05,{ }^{++} \mathrm{P}<0.01$ and ${ }^{++} \mathrm{P}<0.001$ vs. the UVB group. UVB, ultraviolet $\mathrm{B}$; MDA, malondialdehyde; TBARS, thiobarbituric acid reactive substance; SOD, superoxide dismutase; CAT, catalase; GPx, glutathione peroxides; GSH, glutathione; Con, control. 

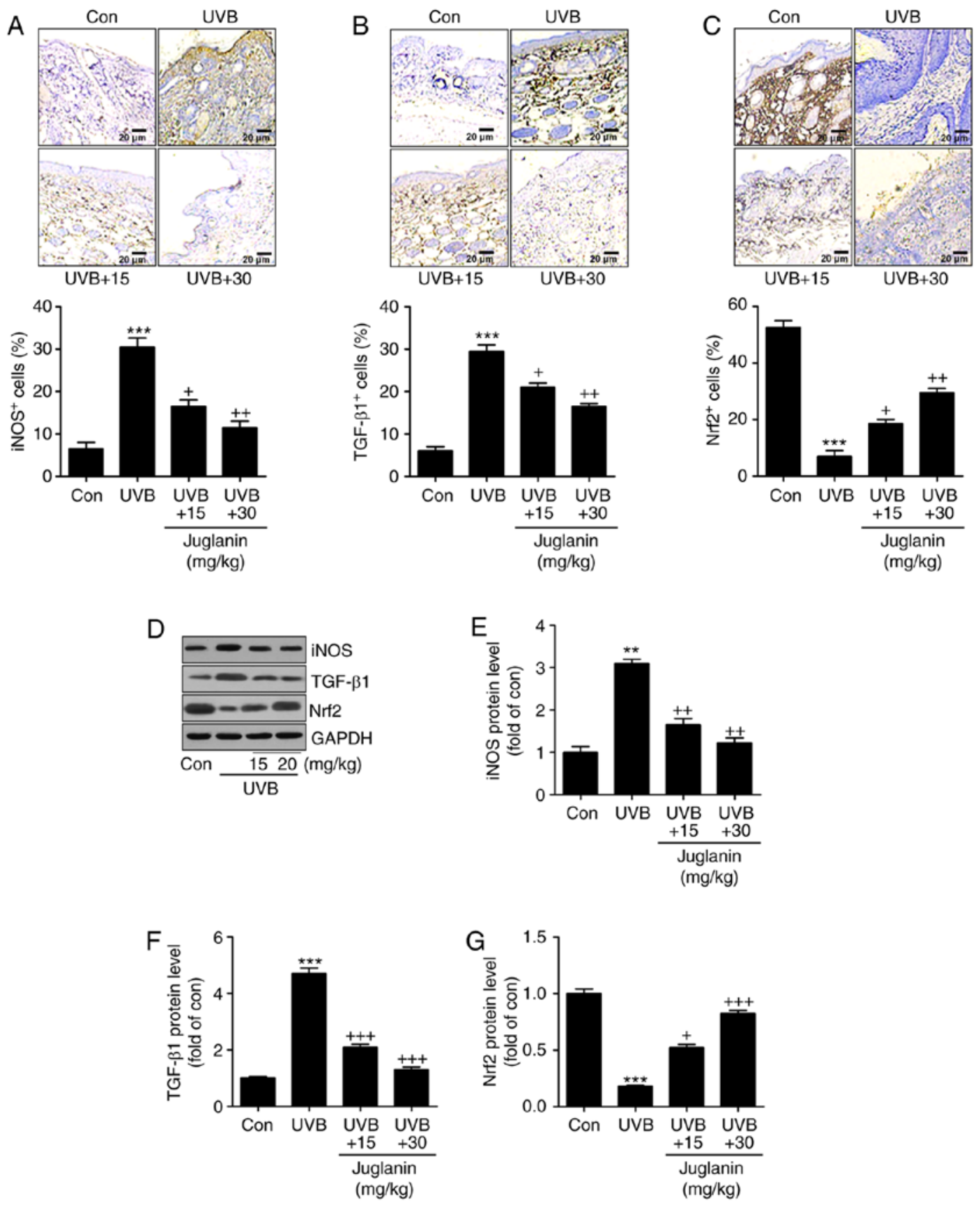

Figure 4. Juglanin inhibits UVB-induced oxidative stress in hairless mice. Immunohistochemical analysis was used to examine (A) iNOS and (B) TGF- $\beta 1$ expression levels in the skin tissue samples from each group of mice. The representative images and the quantification of iNOS and TGF- $\beta 1$ are exhibited. (C) Anti-oxidant Nrf2 expression levels were evaluated by immunohistochemical analysis, and the representative images and quantification are presented. (D) Western blot analysis was performed to assess iNOS, TGF- $\beta 1$ and Nrf2 protein expression levels. The representative band images were exhibited. The quantification of (E) iNOS, (F) TGF- $\beta 1$ and (G) Nrf2 were calculated following western blot analysis using ImageJ software. Data are presented as the mean \pm standard error of the mean $(n=8) .{ }^{* *} \mathrm{P}<0.01$ and ${ }^{* * * *} \mathrm{P}<0.001$ vs. the Con group. ${ }^{+} \mathrm{P}<0.05,{ }^{++} \mathrm{P}<0.01$ and ${ }^{+++} \mathrm{P}<0.001$ vs. the $\mathrm{UVB}$ group. $\mathrm{UVB}$, ultraviolet $\mathrm{B}$; iNOS, inducible nitric oxide synthase; TGF- $\beta 1$, transforming growth factor- $\beta 1$; Nrf2, nuclear factor-E2-related factor 2 ; Con, control.

total groove volume (Fig. 2B), wrinkle area (Fig. 2C), wrinkle volume (Fig. 2D) and the number of wrinkles (Fig. 2E) were significantly increased in the UVB-treated group compared to the Con group $(\mathrm{P}<0.01$ and $\mathrm{P}<0.001$ compared with the Con group). Notably, juglanin treatment markedly reduced these indicators, indicating its role in improving UVB-induced skin damage.

Role of juglanin in UVB-induced MDA, anti-oxidants and TBARS levels in hairless mice. According to previous studies,
UVB irradiation induces oxidative stress, which is associated with membrane lipids (27). In the current study, MDA was evaluated to assess the extent of oxidative stress. In Fig. 3A, MDA levels were identified to be increased in the UVB group, which was an increase of $>2.0$-fold when compared with the control group. In addition, juglanin apparently reduced MDA production. Furthermore, anti-oxidant levels, including SOD, CAT, GPx and GSH, were analyzed to evaluate the role of juglanin in regulating UVB-induced oxidative stress in hairless mice. From Fig. 3B-E, the SOD, CAT and GPX 
A
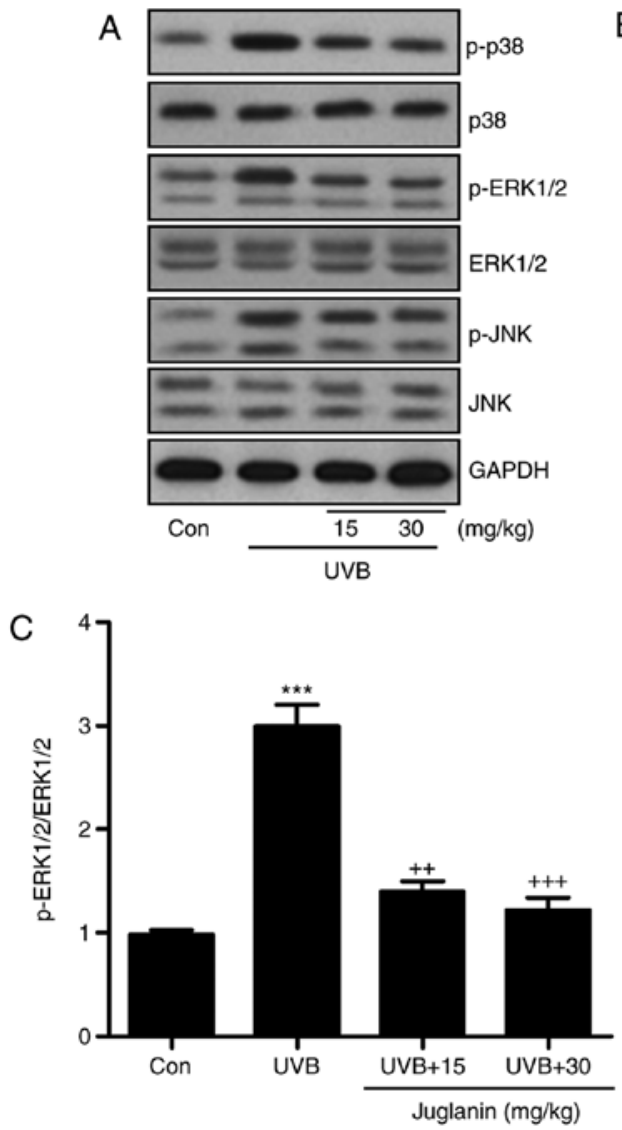

B
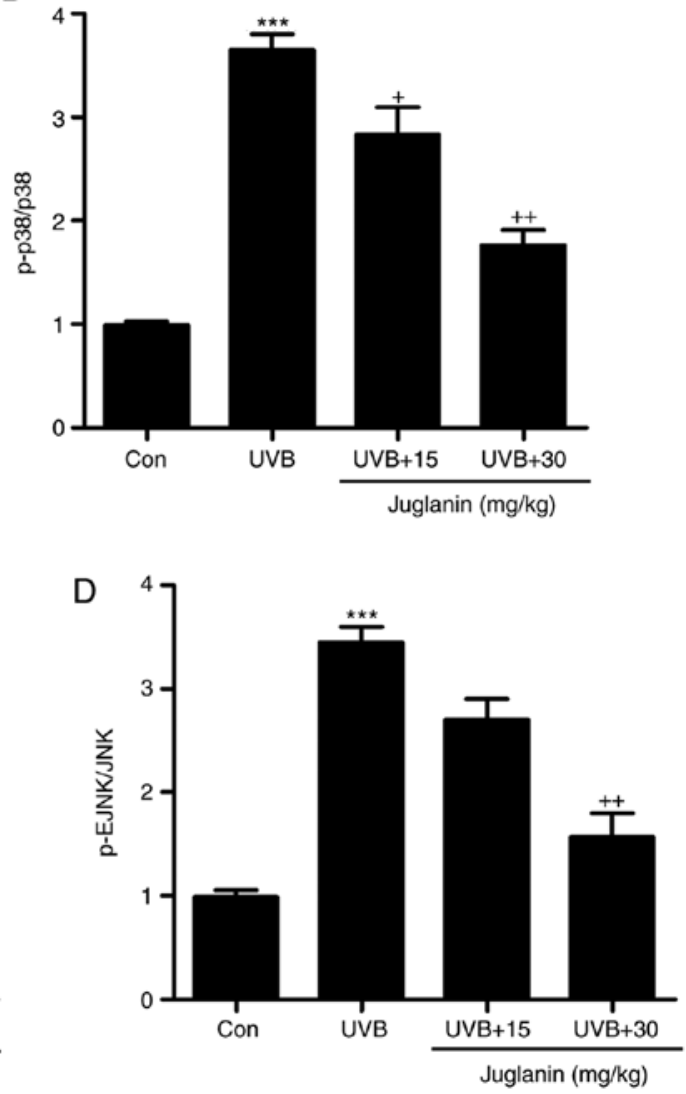

Figure 5. Juglanin impedes ROS generation via MAPK signaling pathway suppression. (A) Western blot analysis was applied to determine p-p38, p-ERK1/2, and p-JNK protein expression levels. (B) The p-p38, (C) p-ERK1/2, and (D) p-JNK expression levels were quantified according to the results of immunoblotting analysis. Data are presented as the mean \pm standard error of the mean $(\mathrm{n}=8)$. ${ }^{* * *} \mathrm{P}<0.001$ vs. the Con group. ${ }^{+} \mathrm{P}<0.05$, ${ }^{++} \mathrm{P}<0.01$ and ${ }^{+++} \mathrm{P}<0.001$ vs. the $\mathrm{UVB}$ group. ROS, reactive oxygen species; MAPK, mitogen activated protein kinases; p, phosphorylated; ERK, extracellular signal-regulated kinase; JNK, c-Jun N-terminal kinases; Con, control; UVB, ultraviolet B.

activities, as well as the GSH levels were markedly reduced following UVB exposure. Treatment with juglanin markedly restored SOD, CAT and GPx activity. The GSH levels were also reversed, which was comparable with the UVB-alone group. TBARS, a lipid peroxidation product, was observed at high levels following UVB irradiation, and juglanin decreased the TBARS levels markedly when compared with the UVB-exposed skin (Fig. 3F). These findings elucidated that juglanin may increase anti-oxidant levels and decrease lipid peroxidation induced by UVB, thus improving oxidative stress.

Juglanin inhibits UVB-induced oxidative stress in hairless mice. According to the results, oxidative stress may be involved in juglanin-ameliorated skin damage triggered by UVB. Therefore, the present study attempted to investigate the potential molecular mechanism by which juglanin attenuated skin injury. In Fig. 4A and B, IHC analysis indicated that iNOS and TGF- $\beta 1$ expression levels were markedly induced in the UVB-alone treatment group. Notably, juglanin exerted a suppressive role in regulating iNOS and TGF- $\beta 1$ expression levels. By contrast, Nrf2 (an essential anti-oxidative factor) was revealed to be reduced in the skin tissue sections from mice with UVB irradiation alone. Additionally, co-treatment with juglanin elevated $\mathrm{Nrf} 2$ expression levels, indicating a potential mechanism to inhibit oxidative stress (Fig. 4C).
Furthermore, in line with the IHC findings, western blotting confirmed the results that iNOS and TGF- $\beta 1$ expression levels were highly induced in the UVB-treated group, and were reversed by juglanin treatment (Fig. 4D-F). In addition, the UVB-induced reduction in Nrf2 protein expression levels was augmented by juglanin exposure (Fig. 4D and G). Thus, the findings illustrated that juglanin-reduced oxidative stress was associated with iNOS and TGF- $\beta 1$ downregulation, as well as Nrf2 upregulation.

The MAPK signaling pathway is closely associated with oxidative stress development (28). p38, ERK1/2, and JNK are three significant members of the MAPK family (29). The present study identified that p38, ERK1/2 and JNK phosphorylation levels were markedly induced in the UVB group, according to western blotting (Fig. 5A). Juglanin administration significantly $(\mathrm{P}<0.05, \mathrm{P}<0.01$ and $\mathrm{P}<0.001$ compared with the UVB group) reduced phosphorylation of $\mathrm{p} 38, \mathrm{ERK} 1 / 2$ and JNK compared to UVB group (Fig. 5B-D). Thus, it is proposed that juglanin-attenuated oxidative stress is associated with MAPK signaling pathway suppression.

Jugalanin inhibits the inflammatory response in UVB-induced hairless mice. Pro-inflammatory cytokine release is important in modulating tissue damage (30). Previous reports indicated that UVB enhanced the inflammatory response in the skin of mice, contributing to skin injury (31). Hence, the current 
A

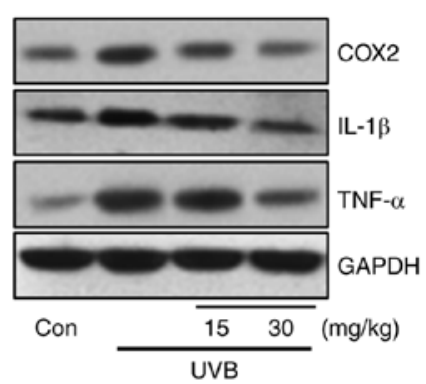

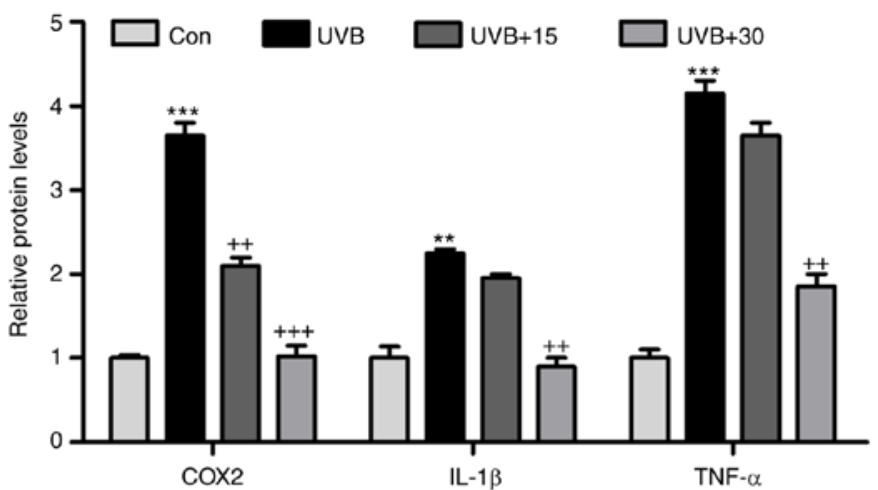

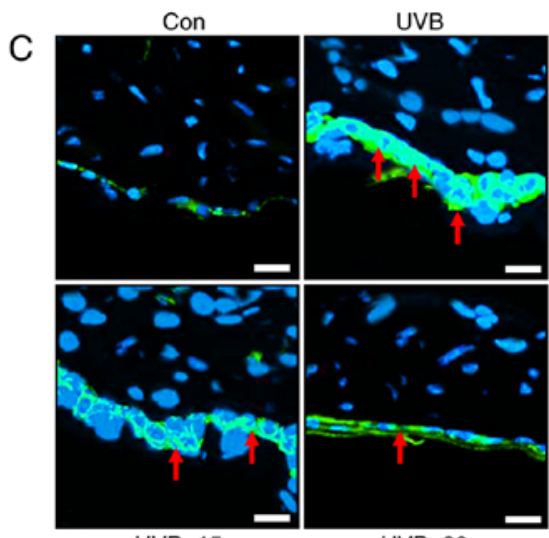

UVB+15
B
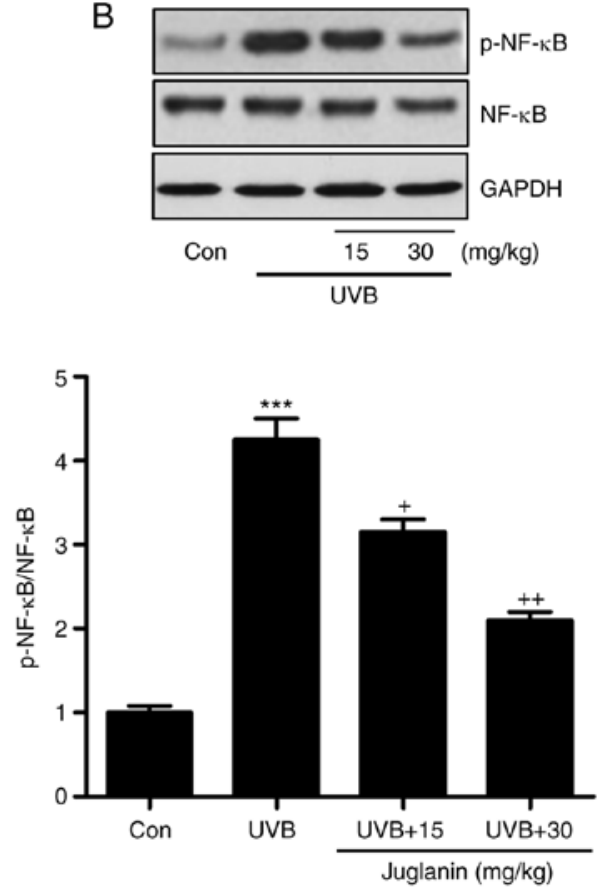

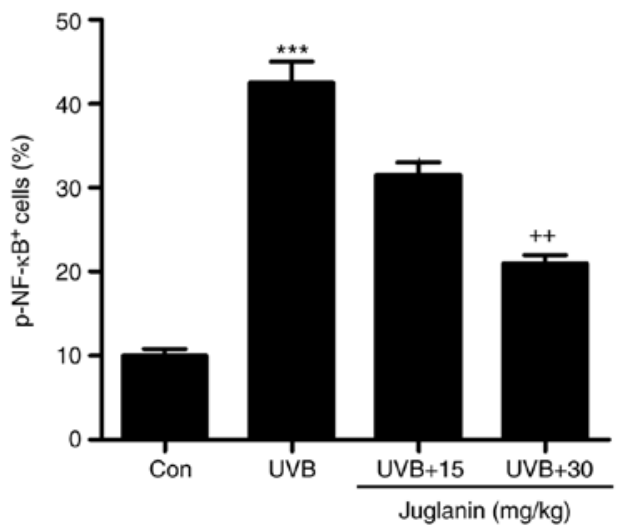

Figure 6. Jugalanin inhibits the inflammatory response in UVB-exposed hairless mice. (A) Western blot analysis was performed to examine COX2, IL-1 $\beta$ and TNF- $\alpha$ expression levels in the skin tissue samples isolated from mice, and the quantified levels are presented. (B) p-NF-кB levels were measured using western blot analysis and quantified. (C) Immunofluorescent assays were performed to determine the NF- $\mathrm{kB}$ phosphorylation levels in the skin sections isolated from the hairless mice. The positive cells expressing p-NF- $\kappa \mathrm{B}$ levels were quantified. Scale bar, $50 \mu \mathrm{m}$. Data are presented as the mean \pm standard error of the mean $(\mathrm{n}=8) .{ }^{* *} \mathrm{P}<0.01$ and ${ }^{* * *} \mathrm{P}<0.001$ vs. the Con group. ${ }^{+} \mathrm{P}<0.05$, and ${ }^{+} \mathrm{P}<0.01$ vs. the UVB group. UVB, ultraviolet $\mathrm{B}$; COX2, cyclic oxidase 2 ;

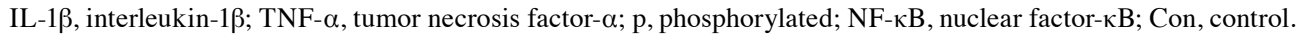

study investigated whether juglanin could perform its role in ameliorating skin damage by altering the inflammatory response. As demonstrated in Fig. 6A, western blotting indicated that pro-inflammatory cytokines, COX2, IL-1 $\beta$, and TNF- $\alpha$ were highly induced in the UVB group, which was consistent with previous studies (32). Notably, juglanin was demonstrated to reduce the expression levels of these cytokines, indicating its role in ameliorating the inflammatory response. NF- $\kappa \mathrm{B}$ is important for pro-inflammatory cytokine secretion via transcription modulation (17). In Fig. 6B, $\mathrm{NF}-\kappa \mathrm{B}$ was phosphorylated in the UVB group, which was inactivated by juglanin administration in a dose-dependent manner. Furthermore, immunofluorescent analysis confirmed that juglanin reduced UVB-induced NF- $\mathrm{KB}$ phosphorylation (Fig. 6C). Thus, the data indicated that juglanin reduces pro-inflammatory cytokine release by dephosphorylating $\mathrm{NF}-\kappa \mathrm{B}$ to attenuate UVB-induced skin damage in mice.

Juglanin ameliorates UVB-induced ROS generation in human skin cells in vitro. In order to further confirm the effects of juglanin on skin damage attenuation, the human epidemical cell line, $\mathrm{HaCaT}$, was included and cells were treated under various conditions. The cytotoxicity of juglanin in $\mathrm{HaCaT}$ was evaluated using MTT analysis. As shown in Fig. 7A, 
A

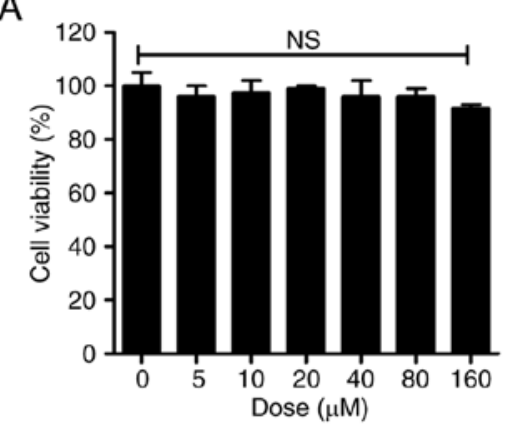

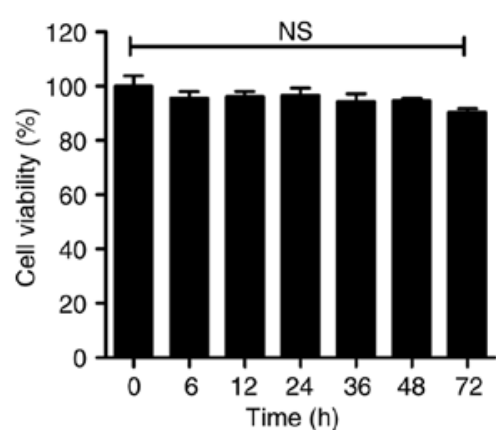

D

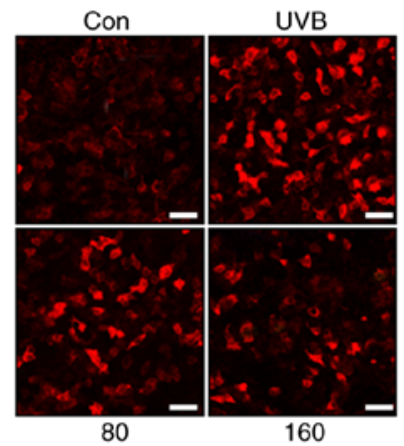

B

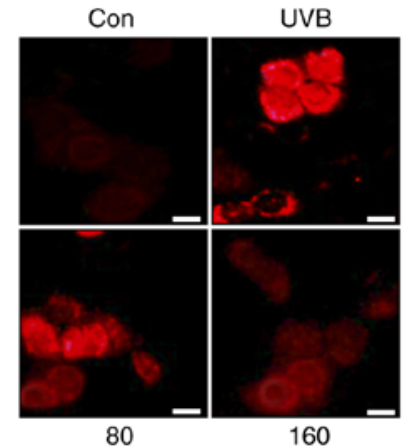

80
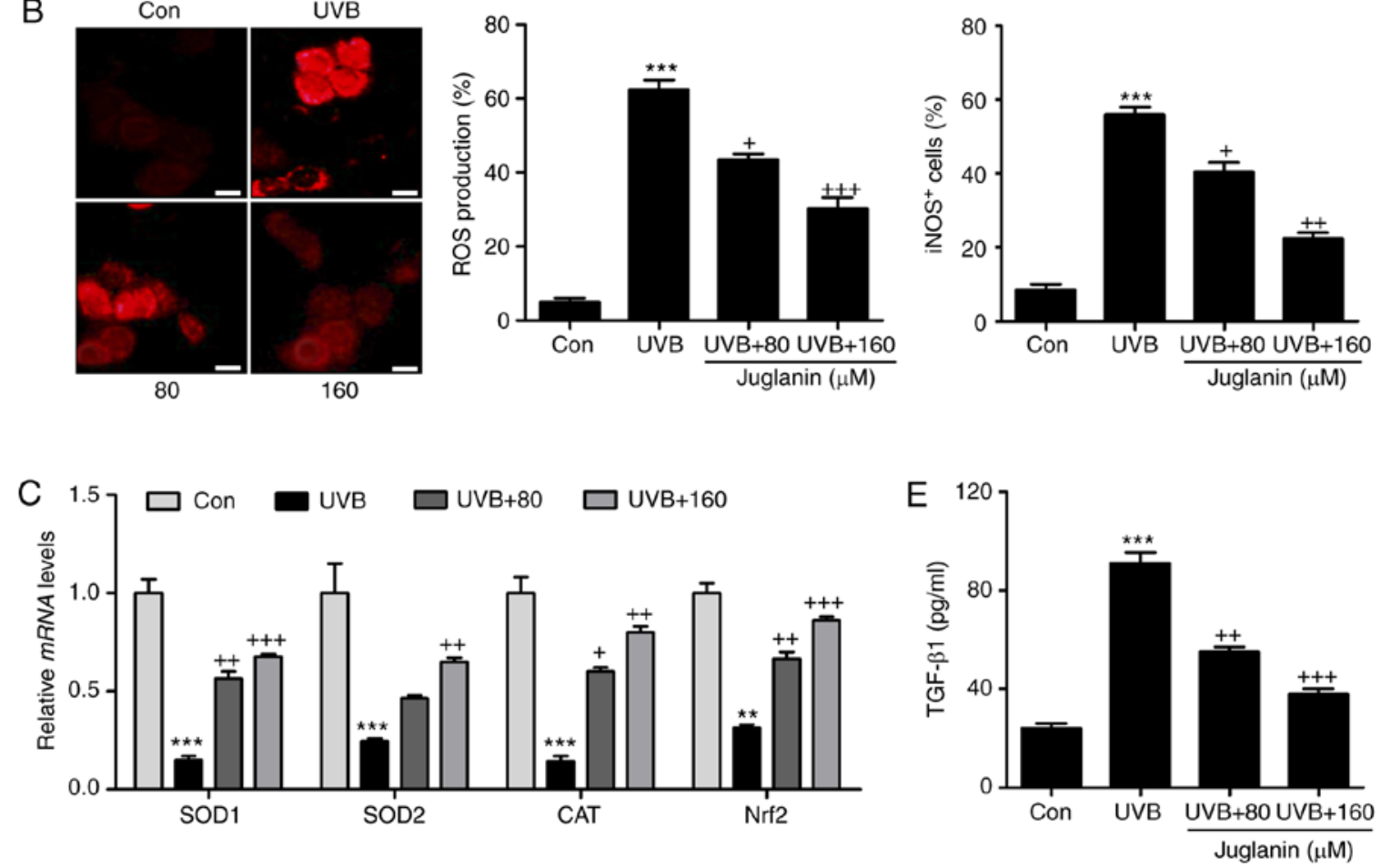

Figure 7. Juglanin ameliorates UVB-induced ROS generation in human skin cells in vitro. (A) Human epidermal cells, HaCaT, were treated with various concentrations of juglanin, ranging from 0 to $160 \mu \mathrm{m}$, for $24 \mathrm{~h}$, followed by cell viability analysis by MTT assay. HaCaT cells were treated with $160 \mu \mathrm{m}$ juglanin for various durations as indicated. MTT analysis was used to evaluate the cell viability for assessing juglanin cytotoxicity in vitro. HaCaT cells were pretreated with juglanin for $12 \mathrm{~h}$, and exposed to $15 \mathrm{~mJ} / \mathrm{cm}^{2} \mathrm{UVB}$ irradiation for $24 \mathrm{~h}$, followed by incubation for another $12 \mathrm{~h}$ in the absence or presence of juglanin at the indicated concentrations. Cells were then harvested for subsequent investigation. (B) ROS production was evaluated using DHE analysis and the quantification of ROS levels is presented. Scale bar, $100 \mu \mathrm{m}$. (C) Reverse transcription-quantitative polymerase chain reaction analysis was performed to evaluate SOD1, SOD2, CAT and Nrf2 mRNA abundance in cells treated under different conditions. (D) The immunofluorescent analysis was used to evaluated iNOS-positive cells following various treatments. Scale bar, $25 \mu \mathrm{m}$. (E) The supernatant of cells was collected after different treatments for TGF- $\beta 1$ assessment using ELISA method and the quantified results are presented. Data are presented as the mean \pm standard error of the mean $(\mathrm{n}=8)$, ${ }^{* *} \mathrm{P}<0.01$ and ${ }^{* * * *} \mathrm{P}<0.001$ vs. the Con group. ${ }^{+} \mathrm{P}<0.05,{ }^{++} \mathrm{P}<0.01$ and ${ }^{++} \mathrm{P}<0.001$ vs. the UVB group. UVB, ultraviolet $\mathrm{B}$; ROS, reactive oxygen species; MTT, 3-(4,5-dimethylthiazol-2-yl)-2,5-diphenyltetrazolium bromide; SOD, superoxide dismutase; CAT, catalase; Nrf2, nuclear factor-E2-related factor 2; iNOS, inducible nitric oxide synthase; TGF- $\beta 1$, transforming growth factor- $\beta 1$; Con, control.

$\mathrm{HaCaT}$ were exposed to various concentrations of juglanin $(0-160 \mu \mathrm{M})$, for $24 \mathrm{~h}$, which was followed by cell viability analysis. No significant difference was observed between the different groups. Additionally, $160 \mu \mathrm{M}$ juglanin was administered to cells for different times as indicated. Consistently, the cell viability was not markedly changed at the highest concentration treatment, even after $72 \mathrm{~h}$. Subsequently, $\mathrm{HaCaT}$ cells were exposed to 80 and $160 \mu \mathrm{M}$ juglanin following UVB exposure for $24 \mathrm{~h}$. DHE analysis was performed to analyze ROS generation. Similar to the results in vivo, ROS production was markedly induced in the HaCaT cells subsequent to UVB irradiation. Notably, juglanin administration reduced ROS generation in a dose-dependent manner (Fig. 7B). RT-qPCR assays were performed to investigate the anti-oxidants, SOD1, SOD2 and CAT and Nrf2 gene expression levels. The data demonstrated that juglanin restored SOD1, SOD2, CAT and Nrf2 mRNA expression levels that were reduced by UVB (Fig. 7C). Furthermore, iNOS fluorescent intensity was downregulated in UVB-treated cells following juglanin exposure (Fig. 7D). Finally, the UVB-induced elevated expression levels of TGF- $\beta 1$ in the supernatant of cells were reduced by co-culture with juglanin (Fig. 7E). These data illustrated that juglanin reduced UVB-induced ROS production in vitro. 
A
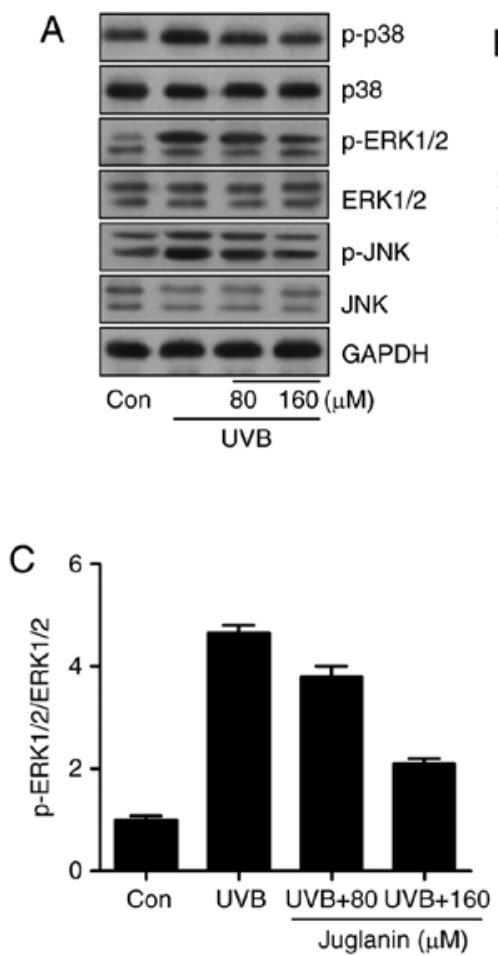
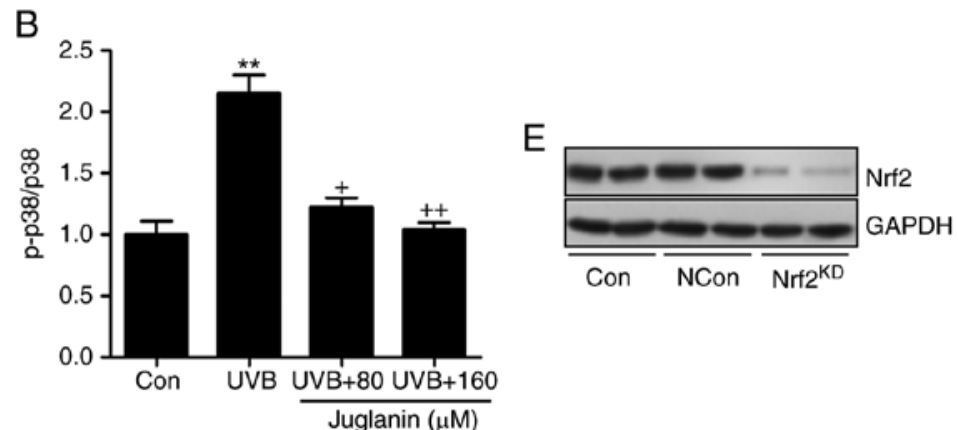

Con NCon Nrf2 ${ }^{\mathrm{KD}}$

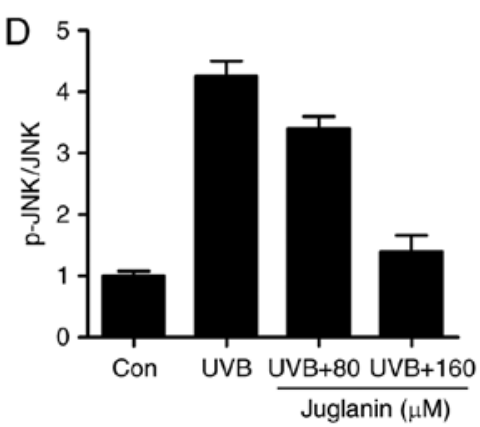

$\mathrm{F}$

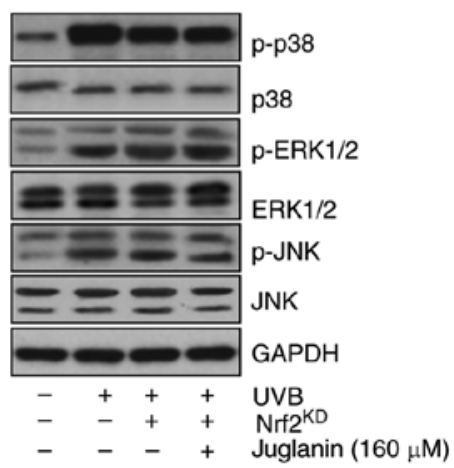

Figure 8. Juglanin-induced suppression of ROS generation is dependent on Nrf2 activity via the inactivation of the MAPK signaling pathway. (A) Western blot analysis was used to calculate p38, ERK1/2 and JNK phosphorylation. (B) p-p38, (C) p-ERK1/2, and (D) p-JNK expression levels were calculated following immunoblotting analysis. (E) Nrf2 was silenced using a specific Nrf2 siRNA sequence. Western blotting was performed to calculate Nrf2 expression levels following knockdown. The representative images are presented. (F) The HaCaT cells were pretreated with juglanin administration in the presence or absence of Nrf2 siRNA for $12 \mathrm{~h}$, and exposed to UVB for $24 \mathrm{~h}$, followed by juglanin administration for another $12 \mathrm{~h}$. Immunoblotting analysis was performed to evaluate p-p38, p-ERK1/2 and p-JNK levels for investigating the role of Nrf2 in juglanin-treated cells following UVB exposure. Data are presented as the mean \pm standard error of the mean $(n=8)$. ${ }^{* *} \mathrm{P}<0.01$ and ${ }^{* * *} \mathrm{P}<0.001$ vs. the Con group. ${ }^{+} \mathrm{P}<0.05,{ }^{++} \mathrm{P}<0.01$ and ${ }^{+++} \mathrm{P}<0.001$ vs. the $\mathrm{UVB}$ group. ROS, reactive oxygen species; MAPK, mitogen activated protein kinase; Nrf2, nuclear factor-E2-related factor 2; UVB, ultraviolet B; ERK, extracellular signal-regulated kinase; JNK, c-Jun N-terminal kinases; Con, control.

Juglanin-induced suppression of ROS generation is dependent on Nrf 2 activity. The MAPK signaling pathway was identified to be involved in juglanin-attenuated skin damage in vivo. Thus, the present study attempted to further confirm its role in vitro. Western blotting indicated that p38, ERK1/2 and JNK phosphorylation was induced by UVB irradiation, which was consistent with the findings in vivo. Similarly, juglanin displayed inhibitory effects (Fig. 8A-D). Nrf2 is a key gene in the regulation of ROS generation (33). The MAPK signaling pathway is regulated by Nrf2 activity, as previously described (34). Thus, to further investigate the molecular mechanism, Nrf2 was silenced using a specific siRNA sequence. Western blotting indicated that Nrf2 knockdown was successfully induced (Fig. 8E). HaCaT cells were then exposed to UVB with or without juglanin and Nrf2 silencing. The findings indicated that subsequent to Nrf2 knockdown, juglanin exhibited no significant effects on $\mathrm{p} 38$, ERK1/2 and JNK phosphorylation in UVB-induced HaCaT cells, indicating that juglanin may depend on Nrf2 activity to modulate MAPK expression, which is involved in ROS production (Fig. 8F).

As juglanin was revealed to suppress the inflammatory response induced by UVB exposure in vivo, further studies were also conducted in vitro to confirm the results of the present study. Consistently, COX2, IL- $1 \beta$ and TNF- $\alpha$ gene expression levels were higher in the UVB-treated group compared with those of the control group, which were reversed following juglanin administration (Fig. 9A). In addition, western blot analysis confirmed the effects of juglanin on reducing pro-inflammatory cytokine secretion in cells subsequent to UVB irradiation (Fig. 9B and C). In addition, $\mathrm{NF}-\kappa \mathrm{B}$ de-phosphorylation by juglanin in UVB-induced HaCaT cells was observed (Fig. 9D). The results indicated that juglanin, indeed, reduced the inflammatory response by regulating NF- $\mathrm{kB}$ activity. Furthermore, there is a close association between Nrf2 and NF- $\mathrm{KB}$ phosphorylation, influencing pro-inflammatory cytokine secretion. Thus, Nrf2 was silenced to further investigate the inflammatory response. As demonstrated in Fig. 9E, following Nrf2 knockdown and similar to MAPK expression, NF- $\kappa \mathrm{B}$ phosphorylation was not reduced following juglanin administration in UVB-induced cells, and the pro-inflammatory cytokines demonstrated a similar trend, which indicated that juglanin-reversed inflammatory response may be dependent on Nrf2 activity.

The results indicated that similar to the treatment with each inhibitor, juglanin significantly $(\mathrm{P}<0.05, \mathrm{P}<0.01$ and $\mathrm{P}<0.001$ compared with the UVB group) reduced UVB-induced $\mathrm{p} 38$, ERK1/2 and JNK phosphorylation in comparison to the UVB group. Notably, the combination of juglanin with each inhibitor further suppressed the activation of p38, ERK1/2 and JNK (Fig. 10A-C). In addition, administration of NF- $\mathrm{KB}$ inhibitor, JSH-23, and juglanin reduced the levels of phosphorylated NF- $\kappa$ B. Though no significant difference was observed between the JSH-23- and juglanin-alone treatment 


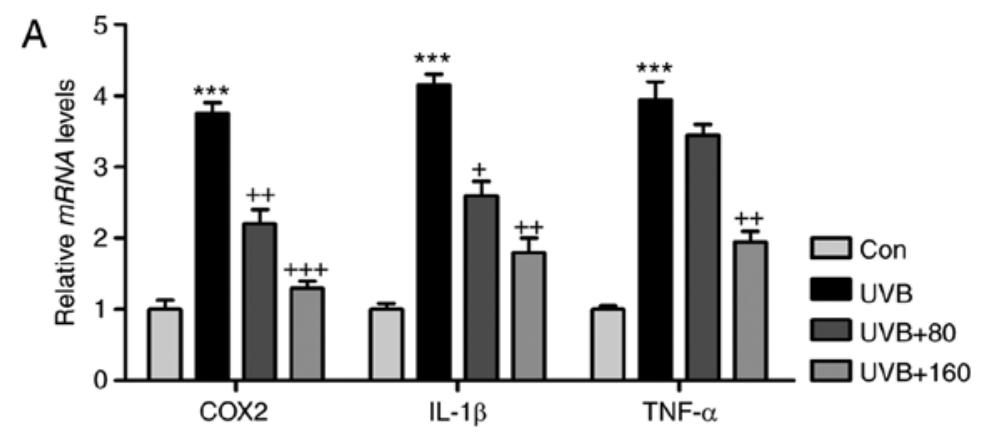

B
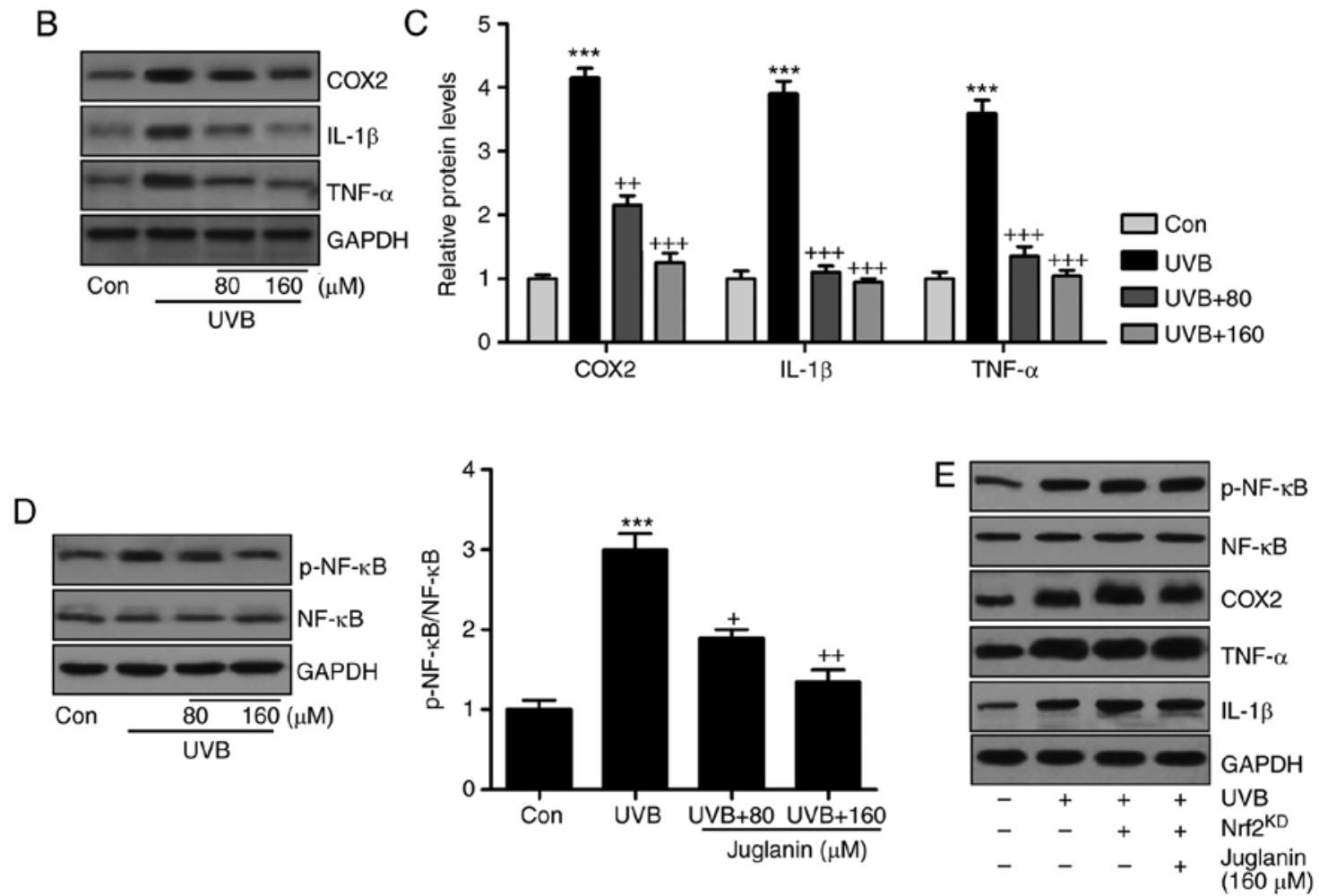

Figure 9. Juglanin reduces the inflammatory response by suppressing NF- $\mathrm{kB}$ associated with Nrf2 activation. (A) Inflammatory cytokines, including COX2, IL-1 $\beta$ and TNF- $\alpha$, were calculated to investigate their gene expression levels using reverse transcription-quantitative polymerase chain reaction analysis. (B) COX2, IL-1 $\beta$ and TNF- $\alpha$ protein expression levels in cells treated under various conditions were assessed via western blotting. (C) The quantification of COX2, IL- $1 \beta$ and TNF- $\alpha$ is presented. (D) Western blotting was performed to evaluate NF-kB phosphorylation in HaCaT cells. (E) The HaCaT cells were pretreated with juglanin in the presence or absence of Nrf2 siRNA for $12 \mathrm{~h}$, and then exposed to UVB for $24 \mathrm{~h}$, followed by juglanin administration for another $12 \mathrm{~h}$. Then, the NF- $\mathrm{KB}$ phosphorylation, COX2, IL-1 $\beta$ and TNF- $\alpha$ protein expression levels were calculated by western blot analysis. Data are presented as the mean \pm standard error of the mean $(n=8) .{ }^{* * * *} \mathrm{P}<0.001$ vs. the Con group. ${ }^{+} \mathrm{P}<0.05,{ }^{++} \mathrm{P}<0.01$ and ${ }^{+++} \mathrm{P}<0.001$ vs. the UVB group. NF- $\mathrm{kB}$, nuclear factor- $-\mathrm{B}$; Nrf2, nuclear factor-E2-related factor 2; COX2, cyclic oxidase 2; IL-1 $\beta$, interleukin-1 $\beta$; TNF- $\alpha$, tumor necrosis factor- $\alpha$; $p$, phosphorylated; NF- $\kappa B$, nuclear factor-kB; Con, control; UVB, ultraviolet B.

and the two combinations, the downregulated expression levels were observed (Fig. 10D). Subsequently, pro-inflammatory cytokines were observed to be reduced by JSH-23- and juglanin-alone treatment, and the two as a combined treatment further impeded COX 2 , IL- $1 \beta$ and TNF- $\alpha$ expression levels, as demonstrated by RT-qPCR analysis (Fig. 10E). These data indicated that juglanin functioned as the inhibitors of MAPKs and $\mathrm{NF}-\kappa \mathrm{B}$, thus attenuating UVB-induced skin injury.

\section{Discussion}

Acute or chronic exposure to UV light, particularly $\mathrm{UVB}$, results in skin damage, which may progress to skin cancer (1-3,35). Annually, there are increasing numbers of newly diagnosed cases of skin cancer reported, and UV exposure is considered to be a major factor leading to skin cancer (36). Given the increased incidence, morbidity, and the cost of the disease, identifying safe, chemo-preventive compounds to protect people from UV light damage has attracted attention (37). Natural products are widely found to inhibit various types of cancer or disease progression to reduce the morbidity or incidence $(38,39)$. Recently, studies have been conducted to investigate the role of juglanin in different types of disease by regulating inflammatory response and ROS generation $(21,22,40)$. Inhibiting inflammation and scavenging ROS generation have been applied in various types of human chronic disease (20). In the present study, H\&E staining demonstrated that juglanin ameliorated 
A

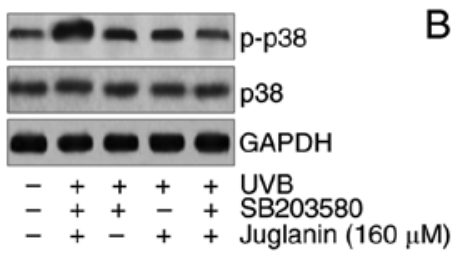

B

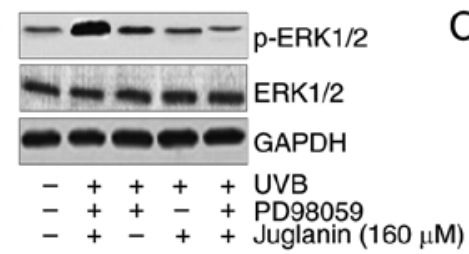

$\mathrm{C}$

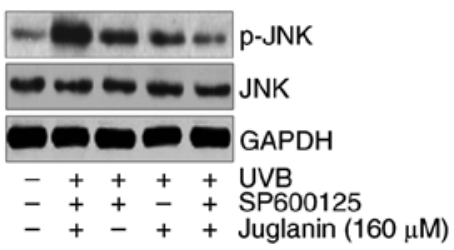

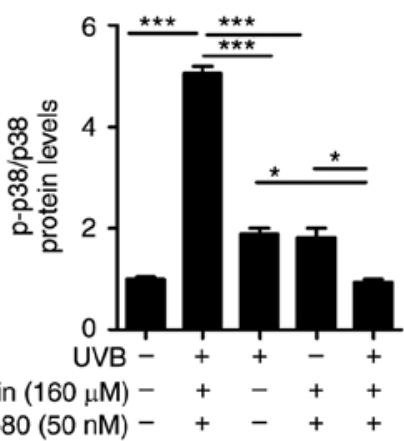

$\begin{array}{rlll}\text { Juglanin }(160 \mu \mathrm{M})- & + & - & + \\ \mathrm{SP} 203580(50 \mathrm{nM})- & + & + & +\end{array}$

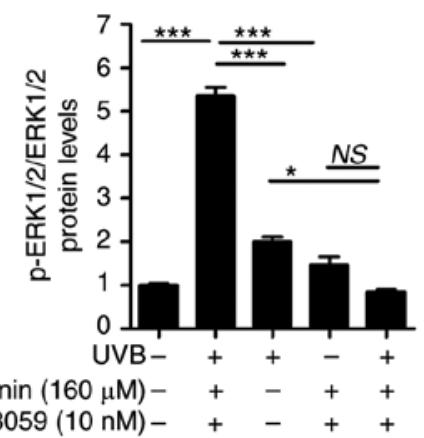

Juglanin $(160 \mu \mathrm{M})-$
PD98059 (10 nM) -
D
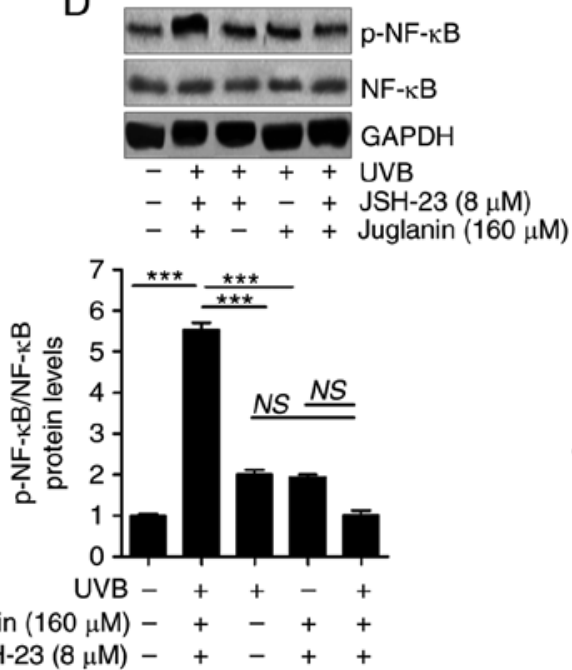

E

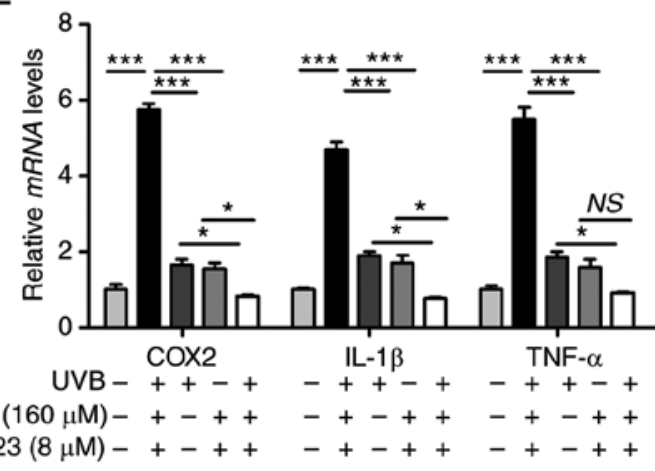

Figure 10. Juglanin functions as the inhibitors of MAPKs and NF- $\mathrm{BB}$ (p65) to attenuate UVB-induced skin injury in vitro. HaCaT cells were pre-treated with (A) SB203580 (50 nM), (B) PD98059 (10 nM) and (C) SP600125 (50 $\mu \mathrm{M})$ for $1 \mathrm{~h}$ or/and with juglanin exposure for $12 \mathrm{~h}$, and then exposed to $15 \mathrm{~mJ} / \mathrm{cm}^{2}$ of UVB irradiation for $24 \mathrm{~h}$, followed by incubation for another $12 \mathrm{~h}$ in the absence or presence of juglanin. Phosphorylated p38, ERK1/2 and JNK were calculated using western blot analysis. (D) The cells were pre-treated with NF- $\kappa \mathrm{B}$ (p65) inhibitor, JSH-23 (8 $\mu \mathrm{M}$ ), for $1 \mathrm{~h}$ or/and with juglanin exposure for $12 \mathrm{~h}$, and then exposed to $15 \mathrm{~mJ} / \mathrm{cm}^{2}$ of UVB irradiation for $24 \mathrm{~h}$, followed by incubation for another $12 \mathrm{~h}$ in the absence or presence of juglanin (160 $\mu \mathrm{M}$ ). Phosphorylated p38 was calculated using western blot analysis. ERK1/2 activation was measured using western blot analysis. (E) The cells after treatment as indicated were harvested for RT-qPCR analysis of COX2, IL-1 $\beta$ and TNF- $\alpha$. Data are represented as the mean \pm SEM, $\mathrm{n}=8$. ${ }^{*} \mathrm{P}<0.05$, and ${ }^{* * * *} \mathrm{P}<0.001$. p, phosphorylated; ERK,

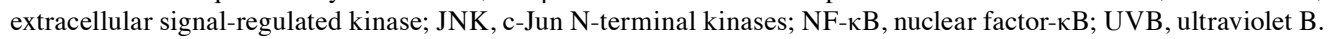

UVB-induced skin damage, as reduced hyperplasia and cell infiltration were observed in the dermis of the mice, directly indicating the potential value of juglanin in preventing skin injury. Tissue MPO activity is an indicator of the neutrophil infiltration at sites where inflammation is present (41). The current data indicated that juglanin administration to mice with UVB-irradiation caused a decrease in MPO activities, further confirming the effects of juglanin on inflammation inhibition.

The skin exposure to UVB has a close association with oxidative stress, which is associated with anti-oxidants and oxidants occurring in tissues (42). Certain major anti-oxidant enzymes, including CAT, GPx and SOD, as well as the limiting enzyme, GSH, have been reported to be depleted in
UVB-induced skin injury, which contribute to the abnormal homeostasis of oxygen radicals in skin tissues (43). Free radicals or other harmful species formed upon UV irradiation exert important effects on diminishing anti-oxidants as previously described (44). Additionally, anti-oxidative enzymes are crucial in DNA damage in UVB-irradiated blood lymphocytes (45). Thus, restoring anti-oxidants is a potential target for drug investigation to suppress UVB-induced tissue injury (46). In the present study, UVB-exposed mice exhibited decreased levels of SOD, CAT, GSH and GPx, while MDA levels increased in the skin of mice, which was consistent with previous studies. Notably, the reduced intracellular ROS generation was observed following juglanin treatment in in vitro studies, demonstrated by DHE analysis. Studies have reported that the 


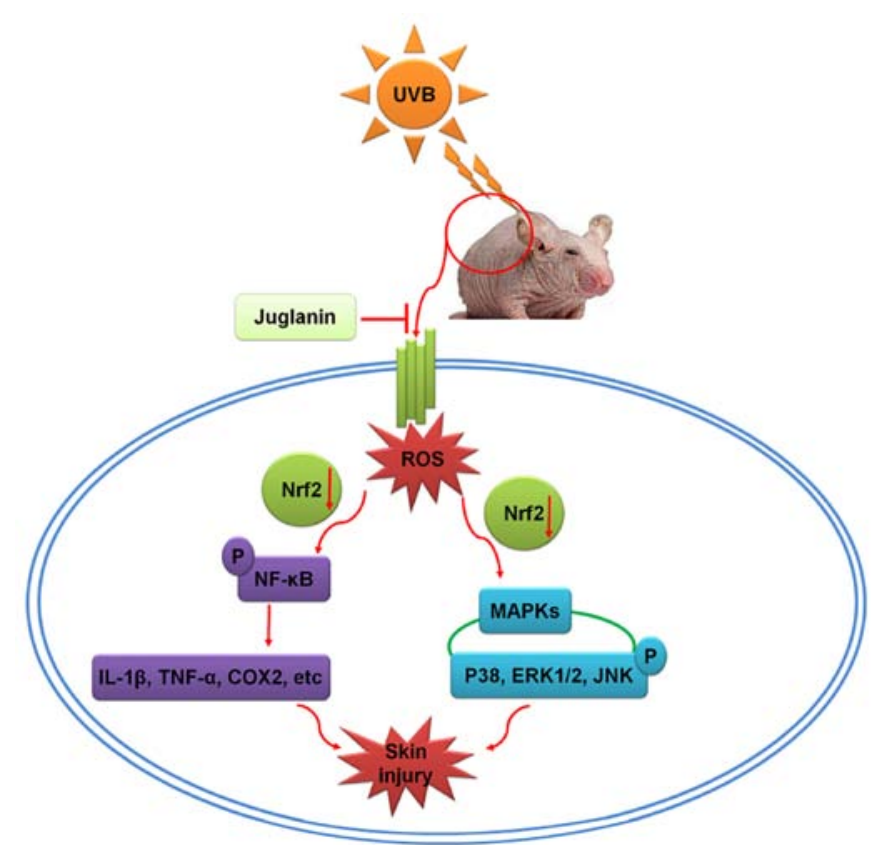

Figure 11. Schematic image of the effects of juglanin on UVB-induced skin damage. Following UVB irradiation, ROS was produced in the skin of hairless mice, contributing to MAPK activation and inflammatory response by activating $N F-\kappa B$, leading to eventual skin damage. The process may be ameliorated by treatment with juglanin, which is dependent on Nrf2 activity. UVB, ultraviolet B; ROS, reactive oxygen species; MAPK, mitogen activated

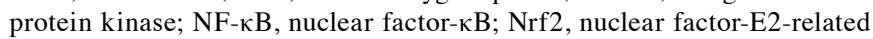
factor 2; COX2, cyclic oxidase 2; IL-1 $\beta$, interleukin-1 $\beta$; TNF- $\alpha$, tumor necrosis factor- $\alpha$; ERK, extracellular signal-regulated kinase; JNK, c-Jun $\mathrm{N}$-terminal kinases.

MAPK family is an essential signaling cascade involved in signal transduction from the membrane to nucleus, influencing ROS generation (47,48). p38, ERK1/2 and JNK, members of the MAPK family, have been reported as key in regulating cell proliferation $(49,50)$. ROS generation in the present study was further supported by $\mathrm{p} 38$, ERK1/2, and JNK phosphorylation in the skin tissue of mice following UVB irradiation, which was ameliorated by juglanin administration, which likely reduced oxidative stress.

The induction of pro-inflammatory cytokines, including TNF- $\alpha$, IL-1 $\beta$, COX-2 and iNOS has been illustrated in pre-cancerous and malignant lesions (51). UV induction of COX2 may result in even the earliest stages of skin injury and inflammation (52). Thus, the suppression of COX2 expression may prevent the skin damage, even cancer development. Furthermore, UVB exposure induces the expression levels of pro-inflammatory cytokines, IL-1 $\beta$ and TNF- $\alpha$ in the skin of mice (53). Overexpression of TGF- $\beta 1$ and iNOS in the mice skin following UVB irradiation is also reported, which enhances skin cancer progression, metastasis as well as epithelial-to-mesenchymal transition at later stages (54). $\mathrm{NF}-\mathrm{kB}$ has been reported in skin damage, whose sustained activation has been elucidated in numerous types of tumor and was involved in various stages of carcinogenesis (55). NF- $\kappa \mathrm{B}$ phosphorylation is crucial for pro-inflammatory cytokine release $(16,56)$. In the present study, UVB irradiation induced Overexpression of COX2, TNF- $\alpha$, IL-1 $\beta$, TGF- $\beta 1$ and iNOS, in line with NF- $\mathrm{KB}$ activity. Notably, juglanin reduced the levels of pro-inflammatory cytokine expression, which is associated with NF- $\kappa$ B de-phosphorylation.

Recently, the photo-chemopreventive effects of the constitutive genetic activation of Nrf2 have been reported in photo-carcinogenesis animal models, and activation of Nrf2 has been considered as a novel and effective molecular strategy for cutaneous photo-protection $(57,58)$. Furthermore, Nrf2 activation may protect fibroblasts against the cytotoxic effects of UVB (59). Nrf2, as the major effector of ROS in the cell, regulates numerous cellular processes $(32,33)$. Nrf2 knockout enhances oxidative stress, and extensive ROS generation suppresses Nrf2 activity, which influences the downstream signaling pathways, including MAPKs and NF- $\mathrm{KB}(34,60)$. To further investigate the association between $\mathrm{Nrf} 2$ activity, and MAPKs and NF- $\mathrm{KB}$ pathways regulated by juglanin, Nrf2 was silenced using specific siRNA sequence in cells in vitro. The data illustrated that Nrf2 knockdown diminished the role of juglanin in reducing UVB-induced MAPKs and NF- $\mathrm{KB}$ phosphorylation, which indicated that juglanin-ameliorated skin damage induced by UVB was likely to be dependent on Nrf2 activity, contributing to MAPKs and NF- $\mathrm{kB}$ inactivation (Fig. 11).

In conclusion, UVB resulted in elevated ROS generation, leading to activation of MAPKs and NF- $\mathrm{KB}$ and promoting the pro-inflammatory cytokine expression, which may contribute to inflammation in mouse skin. In addition, juglanin may suppress ROS production via improving Nrf2 activity, thus ameliorating UVB-induced skin damage. However, further study is still necessary in order to comprehensively reveal the underlying molecular mechanism by which juglanin performs its role against skin injury, in addition to test its safety for further potential uses.

\section{Acknowledgements}

The authors would like to thank the members of the Affiliated Huaian No. 1 People's Hospital of Nanjing Medical University for their guidance.

\section{Funding}

No funding was received.

\section{Availability of data and materials}

All data generated or analyzed during this study are included in this published article.

\section{Authors' contributions}

YHK and SPX performed the experiments and wrote the manuscript. SPX planned the study, wrote the manuscript and organized the experiments.

\section{Ethics approval and consent to participate}

All animal experiments were conducted according to the Guide for the Care and Use of Laboratory Animals, issued by the National Institutes of Health in 1996 and approved by the Institutional Animal Ethics Committee for the Guide for the Care and Use of Laboratory Animals of the Affiliated 
Huaian No. 1 People's Hospital of Nanjing Medical University (Huai'an, China).

\section{Consent for publication}

Not applicable.

\section{Competing interests}

The authors declare that they have no competing interests.

\section{References}

1. Avila Acevedo JG, Espinosa González AM, De Maria y Campos DM, Benitez Flores Jdel C, Hernández Delgado T, Flores Maya S, Campos Contreras J, Muñoz López JL and García Bores AM: Photoprotection of Buddleja cordata extract against UVB-induced skin damage in SKH-1 hairless mice. BMC Complement Altern Med 14: 281, 2014.

2. Meeran SM, Akhtar S and Katiyar SK: Inhibition of UVB-induced skin tumor development by drinking green tea polyphenols is mediated through DNA repair and subsequent inhibition of inflammation. J Invest Dermatol 129: 1258-1270, 2009.

3. Katiyar SK, Matsui MS and Mukhtar H: Kinetics of UV light-induced cyclobutane pyrimidine dimers in human skin in vivo: An immunohistochemical analysis of both epidermis and dermis. Photochem Photobiol 72: 788-793, 2000.

4. Kim JE, Song D, Kim J, Choi J, Kim JR, Yoon HS, Bae JS, Han M, Lee S, Hong JS, et al: Oral supplementation with cocoa extract reduces UVB-induced wrinkles in hairless mouse skin. J Invest Dermatol 136: 1012-1021, 2016.

5. Hwang E, Park SY, Lee HJ, Lee TY, Sun ZW and Yi TH: Gallic acid regulates skin photoaging in UVB-exposed fibroblast and hairless mice. Phytother Res 28: 1778-1788, 2014.

6. Vayalil PK, Mittal A, Hara Y, Elmets CA and Katiyar SK: Green tea polyphenols prevent ultraviolet light-induced oxidative damage and matrix metalloproteinases expression in mouse skin. J Invest Dermatol 122: 1480-1487, 2004.

7. Hong YF, Lee HY, Jung BJ, Jang S, Chung DK and Kim H: Lipoteichoic acid isolated from Lactobacillus plantarum down-regulates UV-induced MMP-1 expression and up-regulates type I procollagen through the inhibition of reactive oxygen species generation. Mol Immunol 67: 248-255, 2015.

8. Thomas-Ahner JM, Wulff BC, Tober KL, Kusewitt DF, Riggenbach JA and Oberyszyn TM: Gender differences in UVB-induced skin carcinogenesis, inflammation, and DNA damage. Cancer Res 67: 3468-3474, 2007.

9. Sullivan NJ, Tober KL, Burns EM, Schick JS, Riggenbach JA, Mace TA, Bill MA, Young GS, Oberyszyn TM and Lesinski GB UV light B-mediated inhibition of skin catalase activity promotes $\mathrm{Gr}-1^{+} \mathrm{CD} 11 \mathrm{~b}^{+}$myeloid cell expansion. J Invest Dermatol 132: 695-702, 2012

10. Zeng SS, Yamashita T, Kondo M, Nio K, Hayashi T, Hara Y, Nomura Y, Yoshida M, Hayashi T, Oishi N, et al: The transcription factor SALL4 regulates stemness of EpCAM-positive hepatocellular carcinoma. J Hepatol 60: 127-134, 2014.

11. Cho JL, Allanson M, Domanski D, Arun SJ and Reeve VE: Estrogen receptor-beta signaling protects epidermal cytokine expression and immune function from UVB-induced impairment in mice. Photoch Photobiolo Sci 7: 120-125, 2008.

12. Yasui H, Hakozaki T, Date A, Yoshii T and Sakurai H: Real-time chemiluminescent imaging and detection of reactive oxygen species generated in the UVB-exposed human skin equivalent model. Biochem Biophys Res Commun 347: 83-88, 2006.

13. Yoon WJ, Ham YM, Lee WJ, Lee NH and Hyun CG: Brown alga Sargassum muticum inhibits proinflammatory cytokines, iNOS and COX-2 expression in macrophage RAW 264.7 cells. Turk J Biol 34: 25-34, 2010.

14. Singh T, Prasad R and Katiyar SK: Regular intake of high-fat diet exacerbates oxidative stress-mediated DNA hypermethylation and activation of Nrf2-Keap1 signaling in UVB-induced skin tumors in SKH-1 hairless mice. Cancer Res 76: 4310, 2016

15. Saw CLL, Yang AY, Huang MT, Liu Y, Lee JH, Khor TO, Su ZY, Shu L, Lu Y, Conney AH and Kong AN: Nrf2 null enhances UVB-induced skin inflammation and extracellular matrix damages. Cell Biosci 4: 39, 2014.
16. Buckman SY, Gresham A, Hale P, Hruza G, Anast J, Masferrer J and Pentland AP: COX-2 expression is induced by UVB exposure in human skin: Implications for the development of skin cancer. Carcinogenesis 19: 723-729, 1998.

17. Muthusamy V and Piva TJ: The UV response of the skin: A review of the MAPK, NFkappaB and TNFalpha signal transduction pathways. Arch Dermatol Res 302: 5-17, 2010.

18. Asgari MM, Chren MM, Warton EM, Friedman GD and White E: Association between nonsteroidal anti-inflammatory drug use and cutaneous squamous cell carcinoma. Arch Dermatol 146: 388-395, 2010.

19. Harris RE, Beebe-Donk J, Doss H and Burr Doss D: Aspirin, ibuprofen, and other non-steroidal anti-inflammatory drugs in cancer prevention: A critical review of non-selective COX-2 blockade (review). Oncol Rep 13: 559-583, 2005.

20. Asgari M, White E and Chren MM: Nonsteroidal anti-inflammatory drug use in the prevention and treatment of squamous cell carcinoma. Dermatol Surg 30: 1335-1342, 2004.

21. Sun ZL, Dong JL and Wu J: Juglanin induces apoptosis and autophagy in human breast cancer progression via ROS/JNK promotion. Biomed Pharmacother 85: 303-312, 2017.

22. Yang HH, Hwangbo K, Zheng MS, Son JK, Kim HY, Baek SH, Choi HC, Park SY and Kim JR: Inhibitory effects of juglanin on cellular senescence in human dermal fibroblasts. J Nat Med 68: 473-480, 2014

23. Zhou GY, Yi YX, Jin LX, Lin W, Fang PP, Lin XZ, Zheng Y and Pan CW: The protective effect of juglanin on fructose-induced hepatitis by inhibiting inflammation and apoptosis through TLR4 and JAK2/STAT3 signaling pathways in fructose-fed rats. Biomed Pharmacother 81: 318-328, 2016.

24. Livak KJ and Schmittgen TD: Analysis of relative gene expression data using real-time quantitative PCR and the 2(-Delta Delta C(T)) method. Methods 25: 402-408, 2001.

25. Nicholls SJ and Hazen SL: The role of myeloperoxidase in the pathogenesis of coronary atery disease. Jpn J Infect Dis 57: S21-S22, 2004

26. Hara Y, Hirao T and Iwai I: Facial expression under stiff stratum corneum leads to strain concentrations, followed by residual wrinkle formation. Int J Cosmetic Sci 39: 66-71, 2017.

27. Calò R and Marabini L: Protective effect of Vaccinium myrtillus extract against UVA- and UVB-induced damage in a human keratinocyte cell line (HaCaT cells). J Photoch Photobio B 132: 27-35, 2014

28. Huang D, Ding Y, Luo WM, Bender S, Qian CN, Kort E, Zhang ZF, VandenBeldt K, Duesbery NS, Resau JH and Teh BT: Inhibition of MAPK kinase signaling pathways suppressed renal cell carcinoma growth and angiogenesis in vivo. Cancer Res 68: 81-88, 2008.

29. Liu J, Chang F, Li F, Fu H, Wang J, Zhang S, Zhao J and Yin D: Palmitate promotes autophagy and apoptosis through ROS-dependent JNK and p38 MAPK. Biochem Biophys Res Commun 463: 262-267, 2015.

30. Fan SH, Zhang ZF, Zheng YL, Lu J, Wu DM, Shan Q, Hu B and Wang YY: Troxerutin protects the mouse kidney from D-galactose-caused injury through anti-inflammation and anti-oxidation. Int Immunopharmacol 9: 91-96, 2009.

31. Ananthi S, Raghavendran HR, Sunil AG, Gayathri V, Ramakrishnan $G$ and Vasanthi HR: In vitro antioxidant and in vivo anti-inflammatory potential of crude polysaccharide from Turbinaria ornata (Marine Brown Alga). Food Chem Toxicol 48: 187-192, 2010.

32. Seo SH and Jeong GS: Fisetin inhibits TNF- $\alpha$-induced inflammatory action and hydrogen peroxide-induced oxidative damage in human keratinocyte $\mathrm{HaCaT}$ cells through PI3K/AKT/Nrf-2-mediated heme oxygenase-1 expression. Int Immunopharmacol 29: 246-253, 2015.

33. Kovac S, Angelova PR, Holmström KM, Zhang Y, Dinkova-Kostova AT and Abramov AY: Nrf2 regulates ROS production by mitochondria and NADPH oxidase. Biochim Biophys Acta 1850: 794-801, 2015.

34. Wang P, Peng X, Wei ZF, Wei FY, Wang W, Ma WD, Yao LP, Fu YJ and Zu YG: Geraniin exerts cytoprotective effect against cellular oxidative stress by upregulation of Nrf2-mediated anti-oxidant enzyme expression via PI3K/AKT and ERK1/2 pathway. Biochim Biophys Acta 1850: 1751-1761, 2015.

35. Muller HK and Woods GM: Ultraviolet radiation effects on the proteome of skin cells. Adv Exp Med Biol 990: 111-119, 2013.

36. Schneider MR: MicroRNAs as novel players in skin development, homeostasis and disease. Br J Dermatol 166: 22-28, 2012 . 
37. Vaid M, Sharma SD and Katiyar SK: Honokiol, a phytochemical from the Magnolia plant, inhibits photocarcinogenesis by targeting UVB-induced inflammatory mediators and cell cycle regulators: Development of topical formulation. Carcinogenesis 31: 2004-2011, 2010.

38. Shehzad A, Lee J, Huh TL and Lee YS: Curcumin induces apoptosis in human colorectal carcinoma (HCT-15) cells by regulating expression of Prp4 and p53. Mol Cells 35: 526-532, 2013.

39. Ying TH, Yang SF, Tsai SJ, Hsieh SC, Huang YC, Bau DT and Hsieh YH: Fisetin induces apoptosis in human cervical cancer HeLa cells through ERK1/2-mediated activation of caspase-8-/caspase-3-dependent pathway. Arch Toxicol 86: 263-273, 2012

40. Paul MK, Bisht B, Darmawan DO, Chiou R, Ha VL, Wallace WD, Chon AT, Hegab AE, Grogan T, Elashoff DA, et al: Dynamic changes in intracellular ROS levels regulate airway basal stem cell homeostasis through Nrf2-dependent Notch signaling. Cell Stem Cell 15: 199-214, 2014.

41. Mäkelä R, Loimaala A, Nenonen A, Mercuri M, Vuori I, Huhtala H, Oja P, Bond G, Koivula T and Lehtimäki T: The association of myeloperoxidase promoter polymorphism with carotid atherosclerosis is abolished in patients with type 2 diabetes. Clin Biochem 41: 532-537, 2008.

42. Bickers DR and Athar M: Oxidative stress in the pathogenesis of skin disease. J Invest Dermatol 126: 2565-2575, 2006.

43. Braga PC, Marabini L, Wang YY, Lattuada N, Calò R, Bertelli A, Falchi M, Dal Sasso M and Bianchi T: Characterisation of the antioxidant effects of Aesculus hippocastanum L. bark extract on the basis of radical scavenging activity, the chemiluminescence of human neutrophil bursts and lipoperoxidation assay. Eur Rev Med Pharmacol Sci 16 (Suppl 3): S1-S9, 2012.

44. Acker T, Fandrey J and Acker H: The good, the bad and the ugly in oxygen-sensing: ROS, cytochromes and prolyl-hydroxylases. Cardiovasc Res 71: 195-207, 2006.

45. Ristow M: Unraveling the truth about antioxidants: Mitohormesis explains ROS-induced health benefits. Nat Med 20: 709-711, 2014.

46. Ki YW, Park JH, Lee JE, Shin IC and Koh HC: JNK and p38 MAPK regulate oxidative stress and the inflammatory response in chlorpyrifos-induced apoptosis. Toxicol Lett 218: 235-245, 2013.

47. Park EJ, Park SW, Kim HJ, Kwak JH, Lee DU and Chang KC: Dehydrocostuslactone inhibits LPS-induced inflammation by p38MAPK-dependent induction of hemeoxygenase-1 in vitro and improves survival of mice in CLP-induced sepsis in vivo. Int Immunopharmacol 22: 332-340, 2014.

48. Brzezianska E and Pastuszak-Lewandoska D: A minireview: The role of MAPK/ERK and PI3K/Akt pathways in thyroid follicular cell-derived neoplasm. Fronti Biosci (Landmark Ed) 16: 422-439, 2011.

49. Hao W, Yuan X, Yu L, Gao C, Sun X, Wang D and Zheng Q: Licochalcone A-induced human gastric cancer BGC-823 cells apoptosis by regulating ROS-mediated MAPKs and PI3K/AKT signaling pathways. Sci Rep 5: 10336, 2015.
50. Mi Y, Xiao C, Du Q, Wu W, Qi G and Liu X: Momordin Ic couples apoptosis with autophagy in human hepatoblastoma cancer cells by reactive oxygen species (ROS)-mediated PI3K/Akt and MAPK signaling pathways. Free Radic Biol Med 90: 230-242, 2016.

51. Damiani E and Ullrich SE: Understanding the connection between platelet-activating factor, a UV-induced lipid mediator of inflammation, immune suppression and skin cancer. Prog Lipid Res 63: 14-27, 2016.

52. Gupta SC, Patchva S and Aggarwal BB: Therapeutic roles of curcumin: Lessons learned from clinical trials. AAPS J 15: 195-218, 2013.

53. Aggarwal BB, Gupta SC and Sung B: Curcumin: An orally bioavailable blocker of TNF and other pro-inflammatory biomarkers. Brit J Pharmacol 16: 1672-1692, 2013.

54. Abbas S, Alam S, Pal A, Kumar M, Singh D and Ansari KM: UVB exposure enhanced benzanthrone-induced inflammatory responses in SKH-1 mouse skin by activating the expression of COX-2 and iNOS through MAP kinases/NF-kB/AP-1 signalling pathways. Food Chem Toxicol 96: 183-190, 2016.

55. Hoesel B and Schmid JA: The complexity of NF- $\mathrm{BB}$ signaling in inflammation and cancer. Mol Cancer 12: 86, 2013.

56. Burris RL, Ng HP and Nagarajan S: Soy protein inhibits inflammation-induced VCAM-1 and inflammatory cytokine induction by inhibiting the NF- $\mathrm{kB}$ and AKT signaling pathway in apolipoprotein E-deficient mice. Eur J Nutr 53: 135-148, 2014.

57. Ramyaa P, Krishnaswamy R and Padma VV: Quercetin modulates OTA-induced oxidative stress and redox signalling in HepG2 cells-upregulation of Nrf2 expression and downregulation of NF- $\kappa$ B and COX-2. Biochim Biophys Acta 1840: 681-692, 2014.

58. Agca CA, Tuzcu M, Hayirli A and Sahin K: Taurine ameliorates neuropathy via regulating $\mathrm{NF}-\kappa \mathrm{B}$ and $\mathrm{Nrf} 2 / \mathrm{HO}-1$ signaling cascades in diabetic rats. Food Chem Toxicol 71: 116-121, 2014.

59. Poulose SM, Bielinski DF, Carey A, Schauss AG and Shukitt-Hale B: Modulation of oxidative stress, inflammation, autophagy and expression of Nrf2 in hippocampus and frontal cortex of rats fed with açaí-enriched diets. Nutr Neurosci 20: 305-315, 2017.

60. Paredes-Gonzalez X, Fuentes F, Jeffery S, Saw CL, Shu L, Su ZY and Kong AN: Induction of NRF2-mediated gene expression by dietary phytochemical flavones apigenin and luteolin. Biopharm Drug Dispos 36: 440-451, 2015.

This work is licensed under a Creative Commons Attribution-NonCommercial-NoDerivatives 4.0 International (CC BY-NC-ND 4.0) License. 